This is the author's manuscript of the article published in final edited form as:

Nelson, A. D., Camilleri, M., Chirapongsathorn, S., Vijayvargiya, P., Valentin, N., Shin, A., ... Murad, M. H. (2016). Comparison of efficacy of pharmacological treatments for chronic idiopathic constipation: a systematic

review and network meta-analysis. Gut, gutjnl-2016-311835. https://doi.org/10.1136/gutjnl-2016-311835

$\mathrm{gim} / \mathrm{c} / \mathrm{c} / \mathrm{man} / \mathrm{Nel}$ son_CIC_systematic_review_4_10_16_without_figures.docx $\mathrm{gim} / \mathrm{c} / \mathrm{c} / \mathrm{man} / \mathrm{Nel}$ son_CIC_systematic_review_4_10_16_without_figures_CLEAN.docx $\mathrm{gim} / \mathrm{c} / \mathrm{c} / \mathrm{man} / \mathrm{Nel}$ son_CIC_systematic_review_3_10_16_Fig1.tif thru Fig3D.tif $4-14-16$

For re-submission to $\underline{\text { GUT }}$

\title{
Comparison of Efficacy of Pharmacological Treatments for Chronic Idiopathic Constipation: A Systematic Review and Network Meta-analysis
}

\author{
Alfred D. Nelson, M.B.B.S. \\ Michael Camilleri, M.D. \\ Sakkarin Chirapongsathorn, M.D., M.Sc. \\ Priya Vijayvargiya, M.D. \\ Nelson Valentin, B.S. \\ Andrea Shin, M.D., M.Sc.* \\ Patricia J. Erwin \\ Zhen Wang, Ph.D." \\ M. Hassan Murad, M.D."
}

From

Clinical Enteric Neuroscience Translational and Epidemiological Research (CENTER) and "Mayo Clinic Evidence-Based Practice Center, Mayo Clinic, Rochester, MN 55905 *Dr. Shin's current affiliation: Indiana University, Indianapolis, IN

Running title: Network meta-analysis of pharmacological agents for treatment of CIC

Word count: 3745 (excluding abstract, summary box, acknowledgements, disclosures, references, table and figure legends)

Key words: bisacodyl, elobixibat, linaclotide, lubiprostone, picosulfate, polyethylene glycol, prucalopride, tegaserod, velusetrag

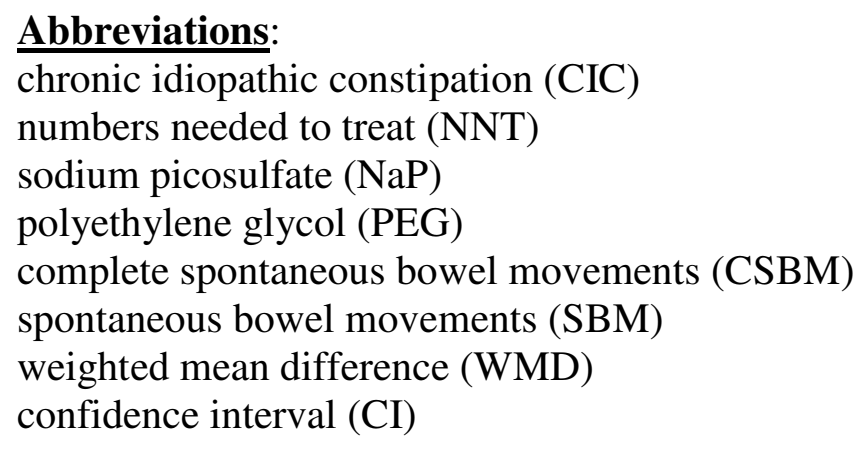


Nelson, Camilleri, et al. - 2 -

serotonin or 5-hydroxytryptamine (5HT)

normal transit constipation (NTC)

slow transit constipation (STC)

high amplitude propagated contractions (HAPC)

Address for correspondence: $\quad$ Michael Camilleri, M.D.

Mayo Clinic

200 First St. S.W.

Charlton Bldg., Rm. 8-110

Rochester, MN 55905

Tele: 507-266-2305

Email: camilleri.michael@mayo.edu 
Nelson, Camilleri, et al. - 3 -

ABSTRACT

Objective: To compare efficacy of pharmacotherapies for chronic idiopathic constipation (CIC) based on comparisons to placebo using Bayesian network meta-analysis.

Data Sources: We conducted searches (inception to May 2015) of MEDLINE, EMBASE, Scopus and Cochrane Central, as well as original data from authors or drug companies for the medications used for CIC.

Study Selection: Phase IIB and phase III randomized, placebo-controlled trials (RCT) of $\geq 4$ weeks' treatment for CIC in adults with Rome II or III criteria for functional constipation; trials included at least 1 of 4 endpoints.

Data Extraction and Synthesis: Two investigators independently evaluated all full text articles that met inclusion criteria and extracted data for primary and secondary endpoints, risk of bias and quality of evidence.

Outcomes: Primary endpoints were $\geq 3$ complete spontaneous bowel movements (CSBM)/week and increase over baseline by $\geq 1 \mathrm{CSBM} /$ week. Secondary endpoints were change from baseline $\left(\Delta_{b}\right)$ in the number of SBM/week and $\Delta_{b}$ CSBM/week.

Results: Twenty-one RCTs (9189 patients) met inclusion and endpoint criteria: 9 prucalopride, 3 lubiprostone, 3 linaclotide, 2 tegaserod, 1 each velusetrag, elobixibat, bisacodyl and sodium picosulphate $(\mathrm{NaP})$. All pre-specified endpoints were unavailable in 4 polyethylene glycol studies. Bisacodyl, NaP, prucalopride and velusetrag were superior to placebo for the $\geq 3$ CSBM/week endpoint. No drug was superior at improving the primary endpoints on network meta-analysis. Bisacodyl appeared superior to the other drugs for the secondary endpoint, $\Delta_{b}$ in number of SBM/week. 
Nelson, Camilleri, et al. - 4 -

Conclusions: Current drugs for CIC show similar efficacy. Bisacodyl may be superior to prescription medications for $\Delta_{\mathrm{b}}$ in the number of SBM/week in CIC.

2

4

5

6

7

8

9

10

11

12

13

14

15

16

17

18

19

20

21

22

23

24

25

26

27

28

29

30

31

32

33

34

35

36

37

38

39

40

41

42

43

44

45

46

47

48

49

50

51

52

53

54

55

56

57

58

59

60 
Nelson, Camilleri, et al. - 5 -

\section{SUMMARY BOX}

What is already known about this subject?

- Fifty percent of patients with chronic idiopathic constipation (CIC) are not completely satisfied with treatment, especially with fiber and laxatives.

- The number needed to treat (NNT), estimated from placebo-controlled clinical trials in CIC comparing pharmacological therapies to placebo, have been reported as follows: osmotic and stimulant laxative, NNT 3; lubiprostone, NNT 4; and prucalopride and linaclotide, both NNT 6.

- The absence of direct comparisons between different drug classes limits comparison of efficacy among treatments.

\section{What are the new findings?}

- Current drugs for CIC show similar efficacy for primary endpoints, which were $\geq 3$ complete spontaneous bowel movements (CSBM)/week and increase over baseline by $\geq 1 \mathrm{CSBM} /$ week.

- Bisacodyl may be superior to prescription medications for change from baseline $(\Delta \mathrm{b})$ $\mathrm{SBM} /$ week in CIC and in comparison with some of the drugs in $\triangle \mathrm{b}$ CSBM/week.

\section{How might it impact on clinical practice in the foreseeable future?}

- Head-to-head trials of active agents are necessary to determine the optimal selection of pharmacological agents for CIC.

- Alternatively, first line medications for patients with CIC should be according to the pathophysiology in order to increase efficacy, such as prokinetics for patients with documented slow transit constipation in the absence of rectal evacuation disorders. 
Nelson, Camilleri, et al. - 6 -

\section{INTRODUCTION}

The estimated global prevalence of chronic idiopathic constipation (CIC) in adults is 14\%.[1] It is usually diagnosed using Rome III symptom criteria,[2] is about twice as common in women and more prevalent over 65 years of age, significantly impacts quality of life, and constitutes a significant financial burden.[3] Treatment of constipation [4] usually starts with nonpharmacological agents like fiber (soluble in preference to nonsoluble fiber and is followed by pharmacological agents if there is no response to fiber.[5] Polyethylene glycol, an osmotic laxative, increases the mean number of stools per week more effectively than placebo or lactulose in adults with CIC, based on direct meta-analyses.[6] It is estimated that about 50\% of patients with CIC were not completely satisfied with treatment due to lack of efficacy or safety concerns, especially with fiber and laxatives (both stimulant and osmotic).

Therefore, this appraisal of the relative efficacy of pharmacotherapies for chronic CIC is clinically relevant. The pharmacological classes of the medications used for CIC are: diphenyl methanes or derivatives (bisacodyl and sodium picosulphate), 5- $\mathrm{HT}_{4}$ receptor agonists (prucalopride, tegaserod and velusetrag), guanylate cyclase $\mathrm{C}$ receptor agonist (linaclotide), chloride channel type 2 opener (lubiprostone) and apical sodium bile acid, (also known as ileal bile acid transport) inhibitor (elobixibat).

The numbers needed to treat (NNT), estimated from placebo-controlled clinical trials comparing these medications to placebo in CIC, were reported as follows: osmotic and stimulant laxative, NNT 3; lubiprostone, NNT 4; and prucalopride and linaclotide, both NNT 6.[6] This might suggest differences in efficacy of the different drug classes; however, this assessment was based on failure to respond to therapy, and vastly different endpoints were used in individual studies. 
The absence of direct comparisons between different drug classes limits comparison of efficacy among treatments to the endpoints currently recommended by the US Food and Drug Administration and is consistent with those of European Medicines Agency.[7] Therefore, our aim was to compare the efficacy of drugs for CIC based on results of each drug compared to placebo using Bayesian network meta-analysis and endpoints consistent with current regulatory agency recommendations.

\section{METHODS}

This systematic review and network meta-analysis was performed according to guidance provided by the Cochrane Handbook for Systematic Reviews of Interventions [8]. It is reported according to the Preferred Reporting Items for Systematic Reviews and Meta-Analyses (PRISMA) guidelines[9]. We followed an a priori established protocol.

\section{Search Methods for Identification of Studies}

A thorough database search was done in May 2015, using Ovid MEDLINE In-Process \& Other Non-Indexed Citations and Ovid MEDLINE (1946 to present), Ovid EMBASE, Scopus databases (1988 to 2015) and Ovid Cochrane CENTRAL (to March 2015) for all the drugs used for treatment of CIC. An expert librarian (PE) conducted the medical literature search with input from the investigators. All the studies for this meta-analysis were identified using a combination of subject headings and free text terms including constipation, chronic constipation, functional constipation, lubiprostone, linaclotide, plecanatide, bisacodyl, sodium picosulfate (NaP), prucalopride, velusetrag, naronapride, polyethylene glycol (PEG), lactulose, elobixibat, fiber, and randomized placebo-controlled trial. Terms were searched in the title, abstract, original title, name of substance word, subject heading word, keyword heading word, protocol supplementary concept word, rare disease supplementary concept word, and unique identifier. The search was 
Nelson, Camilleri, et al. - 8 -

conducted using combinations of these terms by using "and/or". Multiple different combinations of these terms were used. All the abstracts identified using the search strategy were independently evaluated by two investigators (AN and NV) in order to select studies that were eligible for inclusion. For those studies, full text articles were requested. Additional studies were added after review of these drugs in the treatment of CIC in clinicaltrials.gov and manual review of the citations in the publications. All the studies were independently identified by two investigators using well-defined inclusion criteria; conflicts were resolved by consensus between the two investigators after discussing with a third investigator (MC) with content expertise.

\section{Inclusion Criteria}

This systematic review and network meta-analysis was limited only to randomized, placebo-controlled trials of drugs that are either approved by FDA for CIC or drugs with data available for at least one pre-specified endpoint from phase IIB or III randomized, placebocontrolled trials, and $>4$ weeks of treatment. Participants included were adults ( $>18$ years of age) who satisfied Rome II or Rome III criteria for (chronic) functional constipation.

There were no exclusions based on gender, sample size, medical condition, language limitation or medications that are known to affect colonic transit or minimum follow-up period. All eligible studies were required to have placebo as control intervention.

\section{Outcome Assessment}

The current recommended endpoint required by regulatory agencies (specifically, the U.S. Food and Drug Administration) for demonstration of efficacy in CIC trials is $\geq 3$ complete spontaneous bowel movements (CSBM)/week and increase over baseline by $\geq 1 \mathrm{CSBM} /$ week in 9 out of 12 weeks of treatment. However, only randomized, placebo-controlled trials of linaclotide included this endpoint; therefore, we analyzed different endpoints that addressed 
similar outcomes, in order to be consistent in appraising efficacy among studies. The primary endpoints were the proportion of responders, based on $\geq 3 \mathrm{CSBM}$ )/week or the proportion of responders with increase over baseline by $\geq 1 \mathrm{CSBM} /$ week. The secondary endpoints were continuous, quantitative variables: the change from baseline $(\Delta \mathrm{b})$ in the number of spontaneous bowel movements (SBM)/week and $\triangle \mathrm{b}$ CSBM/week. Unfortunately, none of the four available PEG trials included the endpoints selected for our network meta-analysis.

\section{Data Extraction and Management}

Data extraction from the eligible studies was performed by two independent investigators (AN and SC) for the primary and secondary endpoints. Authors of the original publications were contacted by email or by phone requesting missing data in the eligible studies. Data were extracted from manuscripts or databases provided by the investigators or drug companies. Data for primary endpoints were extracted as number of responders and non-responders for each primary endpoint and mean and standard deviation for secondary endpoints.

We also collected data about characteristics of the randomized, placebo-controlled trials, such as study center location (by continents); total number, age and gender of participants in the intervention and control groups; type of intervention; duration of therapy; and criteria for a diagnosis of constipation. Finally, data were extracted to appraise study quality, such as method used for analysis of missing data and loss of follow-up in the intervention and control groups.

\section{Statistical Analysis}

We calculated relative risk for dichotomized outcomes, weighted mean difference (WMD) for continuous outcomes, and related confidence intervals. We performed head-to-head comparisons using DerSimonian-Laird random-effects model. We assessed statistical heterogeneity using the $\mathrm{I}^{2}$ statistic, which represents the proportion of heterogeneity that is not 
Nelson, Camilleri, et al. - 10 -

the result of chance, but reflects true differences across study populations and interventions; $\mathrm{I}^{2}$ $>50 \%$ indicates substantial heterogeneity. Direct comparisons were performed using RevMan v5.3 (The Nordic Cochrane Centre Copenhagen, Denmark).

Network meta-analyses were used to combine effect sizes for all possible comparisons (direct and indirect), regardless of whether they had been compared in trials. In contrast to traditional meta-analyses, which compare one intervention with another one at a time and combine evidence directly from head-to-head clinical trials (if such trials exist), the network meta-analyses allow comparison of all interventions simultaneously. A multivariate metaregression model developed by White was used.[10] The network meta-analyses were conducted using the "network" suite in Stata Version 14.0 (StataCorp LP, College Station, TX, USA).[10]

\section{Sensitivity Analysis}

We examined the effects of the drugs for CIC based on relative risks of the primary and secondary endpoints. We evaluated effect sizes based on therapeutic dose (standard dose group versus high dose) and study quality for prucalopride (low risk of bias versus high risk of bias) for CIC treatment. We also applied the "leave-one-out" method by excluding one study of 24 weeks duration to evaluate the robustness of our findings.

\section{Assessment of Risk of Bias and Publication Bias}

Risk of bias was assessed using Cochrane Handbook for Assessing the Risk of Bias [9]. Two investigators (AN and PV) independently assessed the randomization schedule, allocation concealment, blinding of participants and investigators, blinding of outcome assessment, methods used for missing data, selective reporting, incomplete outcome data, risk of bias for primary and secondary endpoints, and loss of follow up during the treatment period. Due to the 
limited number of studies included in the analyses, we were not able to evaluate potential publication bias.[11]
\end{abstract}

Quality of Evidence

We used the Grading of Recommendation, Assessment, Development and Evaluation (GRADE) Approach to rate the quality of evidence for the estimates derived from the network meta-analyses.[12] Since the studies included were only randomized, placebo-controlled trials, the quality of evidence was considered high in the beginning and down rated based on the assessment of risk of bias, inconsistency, indirectness, imprecision and publication bias. The quality of evidence is rated as high, moderate, low and very low. For indirect estimates, the rating usually starts at lowest rating of contributing direct evidence and can be further down rated based on imprecision and indirectness (mainly intransitivity, i.e., difference in patient populations between studies involved).

\title{
RESULTS
}

\section{Search Results}

The search strategy used identified 546 citations and, among these, we identified 114 articles for review for the full text appraisal. Among the 114 articles, only 18 articles met the inclusion criteria; 96 studies did not meet the inclusion criteria, most often because the endpoints in the trials were different from the selected primary and secondary endpoints, articles did not have original data, or they were nonrandomized studies. The agreement between the investigators (AN and NV) for selection of studies after full text review was high (Kappa statistic $0.86)$.

Three studies which were not identified by the search strategy were added by the investigators. We contacted the authors and drug sponsors of these studies for additional 
Nelson, Camilleri, et al. - 12 -

information regarding the primary and secondary endpoints, and their responses were added to the analysis.

Figure 1 shows the schematic diagram of study selection for the systematic review and meta-analysis; in total, 21 studies were eligible. The study characteristics are summarized in Table 1.

There were 9189 patients in the 21 studies: 9 with prucalopride, $[13,14,15,16,17,18$, 19, 20, 21] 3 with lubiprostone,[22, 23, 24] 3 with linaclotide,[25, 26, 27] 2 with tegaserod,[28, 29] 1 each with Velusetrag,[30] Elobixibat,[31] bisacodyl,[32] and sodium (Na)

picosulphate.[33] The number of drugs, sample size of each drug, and the number of clinical trials included in the network meta-analysis are represented in the form of a network diagram (Figure 2).

The risk of bias of the included studies is summarized in Table 2. Overall, quality was high in 11 , moderate in 9 , and low in 1 study. Downgrading of quality was based most often on unstated details regarding blinding, allocation concealment or management of missing data.

\section{Direct Meta-analysis}

The results of the direct meta-analysis for each primary and secondary endpoint are summarized in Figure 3A-D.

\section{Primary Endpoints}

The data for responder analysis with $\geq 3 \mathrm{CSBM}$ /week were available for 14 randomized, placebo-controlled trials. All six drugs showed a significant increase in $\geq 3 \mathrm{CSBM} /$ week when compared to placebo. Among the three $5 \mathrm{HT}_{4}$ agonists (prucalopride, velusetrag and tegaserod), prucalopride showed higher efficacy [relative risk (RR)] of 1.85 with a $95 \%$ confidence interval (CI) of 1.35 to 2.54 when compared to placebo and with significant heterogeneity of $80.8 \%$ 
( $\mathrm{p}=0.0001)$. Velusetrag had an RR of 4.86 (95\% CI, 2.02 to 11.71); the wider confidence interval may suggest velusetrag might be less efficacious when compared to prucalopride. Stimulant laxatives, bisacodyl and $\mathrm{NaP}$, showed approximately similar efficacy. For linaclotide, RR was 1.96 (95\% CI, 1.12 to 3.44). There was significant heterogeneity between studies of all the drugs appraised using this endpoint $\left(\mathrm{I}^{2}=77.4 \% \mathrm{P}<0.00001\right)$.

For responder analysis with increase over baseline by $\geq 1 \mathrm{CSBM} /$ week, data were available for 15 randomized, placebo-controlled trials; all 7 of the drugs were superior to placebo. Stimulant laxatives (bisacodyl and $\mathrm{NaP}$ ) and elobixibat showed approximately similar efficacy. Prucalopride showed superior efficacy among the $5 \mathrm{HT}_{4}$ agonists, but the heterogeneity between studies was significant $\left(\mathrm{I}^{2}=74.5 \%, \mathrm{p}=0.0001\right)$. Even though the RR for velusetrag was 3.10, which is relatively high when compared to the RR for prucalopride, the $95 \%$ CI with velusetrag was wide (1.83 to 5.24) and overlapped that of prucalopride. Given the overlapping 95\% CI for the two drugs and the significant heterogeneity in the efficacy of prucalopride, the data show overall similar efficacy for prucalopride and velusetrag.

\section{Secondary Endpoints}

Data for $\underline{\Delta}_{\underline{b}} \underline{\mathrm{CSBM} / \text { week }}$ were available only for 5 drugs. All the drugs showed superior efficacy when compared to placebo. Bisacodyl had a weighted mean difference (WMD) of 3.20 (95\% CI, 2.66 to 3.74). Elobixibat and NaP had similar efficacy. For linaclotide, the WMD was 1.57 , with heterogeneity $\mathrm{I}^{2}$ of $0 \%$; this WMD was greater than that of prucalopride which was 0.90 and was also associated with significant heterogeneity $\mathrm{I}^{2}$ of $76.8 \%$.

For the $\underline{\Delta}_{\underline{b}} \underline{\mathrm{SBM} / \text { week}}$, all 7 of the drugs showed superior efficacy relative to placebo. Bisacodyl showed higher efficacy with a WMD of 4.90 when compared to $\mathrm{NaP}$ (3.20). Velusetrag, elobixibat and linaclotide showed similar efficacy with a mean difference (MD) in 
Nelson, Camilleri, et al. - 14 -

the absolute number of $\underline{\Delta}_{\mathrm{b}} \underline{\mathrm{SBM}} \underline{\mathrm{SB}}$ week of $\sim 2.08$. For prucalopride, the WMD was 2.03 , with significant heterogeneity of $63.9 \%$. For lubiprostone, WMD was 1.91 with an $\mathrm{I}^{2}$ of $23.4 \%$.

Network Meta-analysis

$\underline{\text { Responder analysis for } \geq 3 \text { CSBM/week (Table 3A) }}$

Except for tegaserod, all the other drugs (bisacodyl, NaP, prucalopride, velusetrag, linaclotide and elobixibat) showed superior efficacy compared to placebo, but none of the drugs showed superior efficacy when compared to each other in the network meta-analysis.

$\underline{\text { Responder analysis for increase over baseline by } \geq 1 \text { CSBM/week (Table } 3 B)}$

Apart from tegaserod and linaclotide, all the drugs (bisacodyl, NaP, prucalopride and velusetrag) showed superior efficacy when compared to placebo, but none of the drugs showed superior efficacy when compared to each other in the network meta-analysis, with the exception of velusetrag which appears superior when compared to prucalopride and tegaserod.

\section{Change in number of CSBM/week compared to baseline (Table 4A)}

Bisacodyl, NaP, prucalopride, linaclotide and elobixibat showed superior efficacy on the $\Delta_{\mathrm{b}} \mathrm{CSBM}$ /week when compared to placebo. On a network meta-analysis, bisacodyl was superior to $\mathrm{NaP}$, prucalopride and linaclotide. Bisacodyl did not show significant efficacy over elobixibat using this endpoint. NaP showed superior efficacy when compared to prucalopride.

\section{Change in number of SBM/week compared to baseline (Table 4B)}

When compared to placebo on a network meta-analysis, bisacodyl, NaP, prucalopride, velusetrag, linaclotide, elobixibat and lubiprostone treatment showed superior increase in $\Delta_{\mathrm{b}} \mathrm{SBM} /$ week. 
Network meta-analysis suggested that bisacodyl is superior when $\mathrm{NaP}$, prucalopride, velusetrag, linaclotide, elobixibat and lubiprostone are compared to bisacodyl. NaP showed superior efficacy when prucalopride and lubiprostone were compared to $\mathrm{NaP}$.

\section{Quality of Evidence}

We applied the GRADE approach to the main outcome of $\geq 1 \mathrm{CSBM} /$ week because it had the largest number of included trials. In terms of direct estimates of drugs compared to placebo, the quality of evidence was moderate or high for all comparisons. However, most head-to-head comparisons were imprecise (i.e., their CIs were wide and overlapped the null effect). Therefore, the quality of evidence of head-to-head comparisons was mostly low (Table 5).

\section{Sensitivity Analysis}

We conducted sensitivity analyses based on dose of medication (for all drugs for which at least two doses were studied) and risk of bias (for prucalopride). Results were consistent between standard therapeutic dose group compared to high and low dose groups for the primary endpoints and for most of the secondary endpoint analyses (Table 6). An exception was that low dose (in contrast to standard or high dose) prucalopride was not effective compared to placebo for the endpoints of $\geqq 3 \mathrm{CSBM} /$ week and $\Delta \mathrm{b}$ SBM/week.

When analysis was restricted to prucalopride studies at low risk of bias, four trials[13, 16 , $18,19]$ were included and, for the two primary responder analyses, we noted that for $\geq 3 \mathrm{CSBM} /$ week, the RR was $2.12(1.71,2.63)$ and, for increase over baseline by $\geq 1$ CSBM/week, the RR was $1.76(1.54,2.02)$; both had heterogeneity of $0 \%$.

A third sensitivity analysis assessed whether any one study with a markedly different duration [17] had a dominant effect on the pooled RR or heterogeneity. We found that this single study did not markedly affect the summary estimate for the prucalopride studies. Thus, including 
Nelson, Camilleri, et al. - 16 -

the study resulted in RRs for $\geq 3 \mathrm{CSBM} /$ week and for increase over baseline by $\geq 1 \mathrm{CSBM} /$ week of $1.85\left(\mathrm{I}^{2} 80.8 \%\right)$ and $1.54\left(\mathrm{I}^{2} 74.3 \%\right)$, respectively; excluding the study, the RRs were $1.96\left(\mathrm{I}^{2}\right.$ $81.8 \%)$ and $1.63\left(\mathrm{I}^{2} 66.4 \%\right)$, respectively.

\section{DISCUSSION}

Our study has shown that each drug used in the treatment of CIC is superior to placebo, based on the published randomized, placebo-controlled trials. All the drugs are equally efficacious for the primary endpoints of responder analysis with $\geq 3 \mathrm{CSBM} /$ week and increase over baseline by $\geq 1 \mathrm{CSBM} /$ week, in the network meta-analysis. Bisacodyl may be superior to all the other drugs in the secondary endpoint of $\Delta_{b}$ SBM/week and in comparison with some of the drugs in $\Delta_{\mathrm{b}} \mathrm{CSBM} /$ week.

There are, however, limitations in this appraisal of relatively greater efficacy of bisacodyl. There is only one bisacodyl trial with only 4 weeks of treatment compared to other drugs which provided treatment for 12 or 24 weeks. Confirmation of superiority of any of these pharmacotherapies requires direct comparisons of the active interventions using randomized, placebo-controlled trials. A network meta-analysis has distinct features in the absence of trials of direct comparisons of treatments, and may inform judicious selection of treatment. The International Society for Pharmacoeconomics and Outcomes Research (ISPOR) recommends use of multiple treatment meta-analyses in synthesis of data, even with nodal networks, as it allows for more statistically sound assessment of comparative efficacy.[34]

Typically, patients in these randomized, placebo-controlled trials fulfilled Rome II or III criteria for constipation after exclusion of medical and structural conditions. [35] These symptom-based criteria do not differentiate groups, based on the pathophysiology causing CIC. Based on a study of symptoms and pathophysiology in 1411 patients, subgroups of CIC were 
identified, based on pathophysiology: normal transit constipation (NTC) in $\sim 70 \%$, dyssynergic defecation in $\sim 25 \%$, and slow transit constipation (STC) in $\sim 4.5 \%$. [36] In fact, epidemiological studies also have shown that about one-third of people in the community who experience constipation endorse symptoms consistent with dyssynergic defecation.[4] With a preponderance of CIC patients being female and having NTC, the similar efficacy to all the classes of drugs for the treatment of CIC is not surprising.

Prior randomized, placebo-controlled trials included in this analysis did not subgroup patients according to pathophysiology; hence, we are unable to report efficacy in subgroups of CIC. It is conceivable that patients with STC might respond better to treatment with agents that have significant effects on colonic motor function. Several of the agents evaluated in this network meta-analysis accelerate colonic transit, including intestinal secretagogues (lubiprostone,[37] linaclotide,[38] and the bile acid transport inhibitor, elobixibat [39]) and prokinetic agents (prucalopride,[40] tegaserod,[41] and bisacodyl [42]). However, among all these drugs, only prucalopride [43] and bisacodyl have been shown to increase the number of high amplitude propagated contractions (HAPC), which are highly propulsive in the colon.[44] Lubiprostone did not induce colonic high amplitude contractions.[45]

A recent consensus monograph, based on meta-analysis of treatments of CIC, gave strong recommendation for treatment with fiber, osmotic laxatives (PEG, lactulose), stimulant laxatives (NaP and bisacodyl), prucalopride, linaclotide and lubiprostone.[46] However, the quality of evidence was considered moderate in some of the trials, there were no direct comparisons between active drugs, and the analysis used as primary endpoint the failure to respond to therapy. This appraisal actually combined in non-responder status failure to respond to different endpoints in each trial. In addition, the secondary endpoints evaluated did not differentiate SBM from 
Nelson, Camilleri, et al. - 18 -

CSBM. Despite these methodological differences, our direct and network meta-analyses confirm the general conclusion of the prior report regarding the efficacy of each intervention relative to placebo with reference to the primary endpoints (which are the components of the endpoint currently recommended by FDA), although there is a possible difference in efficacy on secondary endpoints between bisacodyl and other drugs.

Our study has some limitations. There is only one randomized, placebo-controlled trial for 4 of the drugs included in the meta-analysis ( $\mathrm{NaP}$, bisacodyl, velusetrag and elobixibat), and osmotic laxatives such as PEG, lactulose, and magnesium salts were not included, since the endpoints in those studies were not uniform or consistent with the inclusion criteria. This particularly applies to the trials with PEG. $[47,48,49,50]$ There is one randomized, placebocontrolled trial directly comparing PEG3350 + electrolytes (PEG3350+E) to prucalopride treatment,[51] but this was a single-center study conducted in a controlled environment on patients many of whom had features suggesting evacuation disorder at baseline: $\sim 50 \%$ reported sensation of anal blockage and 15\% manual maneuvers to facilitate defecation. Moreover, the primary endpoint was the proportion of patients having $\geq 3$ SCBMs during the last week of treatment in a 4-week trial, rather than the entire treatment period, and the randomized, placebocontrolled trial showed non-inferiority of PEG3350 + E to prucalopride, consistent with our general conclusion that the approved pharmacotherapies for CIC have similar efficacy.

Other limitations in our network meta-analysis are the variability in the duration of treatment (4 to 24 weeks) and safety and adverse events for the drugs were not analyzed in our study. Another limitation is that, in many of these pivotal clinical trials, bisacodyl is often used as the rescue medication, and the impact of this on the "placebo" arms could not be appraised as it is not reported in detail in the trials. It is also conceivable that the high number of prucalopride 
Nelson, Camilleri, et al. - 19 -

trials impacted the relative assessment of efficacy by reducing the width of the confidence interval of the RR; therefore, we have interpreted cautiously the RR differences between prucalopride and velusetrag which was the only medication identified as less efficacious than prucalopride in the statistical analysis.

Strengths in our study design and network meta-analysis include trials with similar patient population, comparators, outcome assessments, and trial design; application of the GRADE approach to provide an objective and transparent assessment of the quality of evidence for evaluating comparative efficacy of these agents;[52] and the inclusion of the responder analyses as well as secondary endpoints which are very relevant in view of differences in baseline SBM and CSBM between studies.[53]

In conclusion, network meta-analysis shows that current pharmacotherapies for CIC have similar efficacy. Based on secondary endpoints, bisacodyl may be superior to other medications prescribed for CIC; however, bisacodyl is associated with abdominal cramps and diarrhea. In the future, head-to-head trials of active agents are necessary to determine the efficacy and adverse effects in order to facilitate optimal selection of pharmacological agents for CIC instead of the current choice based on failure of prior drugs. 
Acknowledgements: We thank Dr. Fabio Cataldi and Dr. Debra Silberg (Shire Pharmaceuticals, Turnhout, Belgium), the late Dr. Hans Graffner (Albireo, Göteborg, Sweden), Dr. Sabine Niedermeier (Boehringer Ingelheim Pharma GmbH \& Co. KG, Ingelheim, Germany), Dr. Peter Lichtlen (Sucampo AG, Bethesda, MD), Dr. Fukudo Shin (Tohoku University, Sendai, Japan), Dr. Michael A Kamm (University of Melbourne, Melbourne, Australia) and Dr. Stefan MuellerLissner (Lehrkrankenhaus der Charité, Universitätsmedizin, Berlin, Germany) for providing access to clinical trial data for medications reviewed in this article.

Funding: Dr. Camilleri is supported by grant R01-DK92179 from National Institutes of Health for studies on lower functional gastrointestinal disorders.

Competing Interests: Dr. Camilleri received grants for research on pharmacodynamics of prucalopride, velusetrag, elobixibat, linaclotide, and lubiprostone in the past decade. Dr. Camilleri serves as an advisor to Albireo, Rhythm, and Theravance, with compensation for his time serving as an advisor paid to his employer, Mayo Clinic, not to himself personally. The other authors have no competing interests.

\section{Authors' contributions:}

Alfred D. Nelson: concept development, data analysis, selection of articles, authorship Michael Camilleri: concept development, data analysis, selection of articles, authorship Sakkarin Chirapongsathorn: network meta-analysis, authorship Priya Vijayvargiya: assessment of study quality, authorship Nelson Valentin: selection of articles to be included after the literature search, authorship Andrea Shin: analysis of data on $5 \mathrm{HT}_{4}$ agonists, authorship Patricia J. Erwin: literature search for systematic review, authorship Zhen Wang: network meta-analysis, authorship M. Hassan Murad: systematic review and network meta-analysis, authorship 


\section{References}

1 Suares NC, Ford AC. Prevalence of, and risk factors for, chronic idiopathic constipation in the community: systematic review and meta-analysis. Am J Gastroenterol 2011;106:1582-91; quiz $1,92$.

2 Longstreth GF, Thompson WG, Chey WD, et al. Functional Bowel Disorders. Gastroenterology 2006;130:1480-91.

3 Peery AF, Crockett SD, Barritt AS, et al. Burden of Gastrointestinal, Liver, and Pancreatic Diseases in the United States. Gastroenterology 2015;149:1731-41.e3.

4 Bharucha AE, Pemberton JH, Locke III GR. American Gastroenterological Association Technical Review on Constipation. Gastroenterology 2013;144:218-38.

5 Voderholzer WA, Schatke W, Muhldorfer BE, et al. Clinical response to dietary fiber treatment of chronic constipation. Am J Gastroenterol 1997;92:95-8.

6 Ford AC, Suares NC. Effect of laxatives and pharmacological therapies in chronic idiopathic constipation: systematic review and meta-analysis. Gut 2011;60:209-18.

7 http://www.ema.europa.eu/docs/en_GB/document_library/Scientific_guideline/ 2014/02/WC500162134.pdf

8 Higgins JP, Strene JAC. Cochrane Handbook for Systematic Reviews of interventions In: Higgins JP and Green S ed. Available from www.cochrane-handbook.org.: The Cochrane Collaboration; 2011.

9 Hutton B, Salanti G, Caldwell DM, et al. The PRISMA Extension Statement for Reporting of Systematic Reviews Incorporating Network Meta-analyses of Health Care Interventions: Checklist and ExplanationsPRISMA Extension for Network Meta-analysis. Annals of Internal Medicine 2015;162:777-84.

10 White IR, Barrett JK, Jackson D, et al. Consistency and inconsistency in network metaanalysis: model estimation using multivariate meta-regression. Research Synthesis Methods 2012;3:111-25.

11 Ioannidis JP, Trikalinos TA. The appropriateness of asymmetry tests for publication bias in meta-analyses: a large survey. CMAJ 2007;176:1091-6.

12 Guyatt G, Oxman AD, Sultan S, et al. GRADE guidelines: 11. Making an overall rating of confidence in effect estimates for a single outcome and for all outcomes. Journal of Clinical Epidemiology 2013;66:151-7.

13 Camilleri M, Kerstens R, Rykx A, et al. A Placebo-Controlled Trial of Prucalopride for Severe Chronic Constipation. New England Journal of Medicine 2008;358:2344-54.

14 Coremans G, Kerstens R, De Pauw M, et al. Prucalopride is effective in patients with severe chronic constipation in whom laxatives fail to provide adequate relief. Results of a double-blind, placebo-controlled clinical trial. Digestion 2003;67:82-9.

15 Ke M, Zou D, Yuan Y, et al. Prucalopride in the treatment of chronic constipation in patients from the Asia-Pacific region: a randomized, double-blind, placebo-controlled study. Neurogastroenterology \& Motility 2012;24:999-e541.

16 Müller-lissner S, Rykx A, Kerstens R, et al. A double-blind, placebo-controlled study of prucalopride in elderly patients with chronic constipation. Neurogastroenterology \& Motility 2010;22:991-e255.

17 Piessevaux H, Corazziari E, Rey E, et al. A randomized, double-blind, placebo-controlled trial to evaluate the efficacy, safety, and tolerability of long-term treatment with prucalopride. Neurogastroenterology \& Motility 2015;27:805-15. 
Nelson, Camilleri, et al. - 22 -

18 Quigley EMM, Vandeplassche L, Kerstens R, et al. Clinical trial: the efficacy, impact on quality of life, and safety and tolerability of prucalopride in severe chronic constipation - a 12week, randomized, double-blind, placebo-controlled study. Alimentary Pharmacology \& Therapeutics 2009;29:315-28.

19 Tack J, van Outryve M, Beyens G, et al. Prucalopride (Resolor) in the treatment of severe chronic constipation in patients dissatisfied with laxatives. Gut 2009;58:357-65.

20 Emmanuel AV, Roy AJ, Nicholls TJ, et al. Prucalopride, a systemic enterokinetic, for the treatment of constipation. Alimentary Pharmacology \& Therapeutics 2002;16:1347-56.

21 Yiannakou Y, Piessevaux H, Bouchoucha M, et al. A Randomized, Double-Blind, Placebo-Controlled, Phase 3 Trial to Evaluate the Efficacy, Safety, and Tolerability of Prucalopride in Men With Chronic Constipation. Am J Gastroenterol 2015;110:741-8. 22 Johanson JF, Morton D, Geenen J, et al. Multicenter, 4-Week, Double-Blind, Randomized, Placebo-Controlled Trial of Lubiprostone, a Locally-Acting Type-2 Chloride Channel Activator, in Patients With Chronic Constipation. Am J Gastroenterol 2008;103:170-7.

23 Barish CF, Drossman D, Johanson JF, et al. Efficacy and safety of lubiprostone in patients with chronic constipation. Dig Dis Sci 2010;55:1090-7.

24 Fukudo S, Hongo M, Kaneko H, et al. Lubiprostone Increases Spontaneous Bowel Movement Frequency and Quality of Life in Patients With Chronic Idiopathic Constipation. Clinical Gastroenterology and Hepatology 2015;13:294-301.e5.

25 Lacy BE, Schey R, Shiff SJ, et al. Linaclotide in Chronic Idiopathic Constipation Patients with Moderate to Severe Abdominal Bloating: A Randomized, Controlled Trial. PLoS ONE 2015;10:e0134349.

26 Lembo AJ, Kurtz CB, MacDougall JE, et al. Efficacy of Linaclotide for Patients With Chronic Constipation. Gastroenterology 2010;138:886-95.e1.

27 Lembo AJ, Schneier HA, Shiff SJ, et al. Two Randomized Trials of Linaclotide for Chronic Constipation. New England Journal of Medicine 2011;365:527-36.

28 Fried M, Johanson JF, Gwee KA, et al. Efficacy of Tegaserod in Chronic Constipation in Men. Am J Gastroenterol 2007;102:362-70.

29 Kamm MA, Muller-Lissner S, Talley NJ, et al. Tegaserod for the Treatment of Chronic Constipation: A Randomized, Double-Blind, Placebo-Controlled Multinational Study. Am J Gastroenterol 2005;100:362-72.

30 Goldberg M, Li YP, Johanson JF, et al. Clinical trial: the efficacy and tolerability of velusetrag, a selective 5-HT4 agonist with high intrinsic activity, in chronic idiopathic constipation - a 4-week, randomized, double-blind, placebo-controlled, dose-response study. Alimentary Pharmacology \& Therapeutics 2010;32:1102-12.

31 Chey WD, Camilleri M, Chang L, et al. A Randomized Placebo-Controlled Phase IIb Trial of A3309, A Bile Acid Transporter Inhibitor, for Chronic Idiopathic Constipation. Am J Gastroenterol 2011;106:1803-12.

32 Kamm MA, Mueller-Lissner S, Wald A, et al. Oral Bisacodyl Is Effective and WellTolerated in Patients With Chronic Constipation. Clinical Gastroenterology and Hepatology 2011;9:577-83.

33 Mueller-Lissner S, Kamm MA, Wald A, et al. Multicenter, 4-Week, Double-Blind, Randomized, Placebo-Controlled Trial of Sodium Picosulfate in Patients With Chronic Constipation. Am J Gastroenterol 2010;105:897-903. 
34 Hoaglin DC, Hawkins N, Jansen JP, et al. Conducting indirect-treatment-comparison and network-meta-analysis studies: report of the ISPOR Task Force on Indirect Treatment Comparisons Good Research Practices: part 2. Value Health 2011;14:429-37.

35 Locke III GR, Pemberton JH, Phillips SF. AGA technical review on constipation. Gastroenterology 2000;119:1766-78.

36 Nullens S, Nelsen T, Camilleri M, et al. Regional colon transit in patients with dyssynergic defaecation or slow transit in patients with constipation. Gut 2012;61:1132-9.

37 Camilleri M, Bharucha AE, Ueno R, et al. Effect of a selective chloride channel activator, lubiprostone, on gastrointestinal transit, gastric sensory, and motor functions in healthy volunteers. American Journal of Physiology - Gastrointestinal and Liver Physiology 2006;290:G942-G7.

38 Andresen V, Camilleri M, Busciglio IA, et al. Effect of 5 Days Linaclotide on Transit and Bowel Function in Females With Constipation-Predominant Irritable Bowel Syndrome. Gastroenterology 2007;133:761-8.

39 Wong BS, Camilleri M, McKinzie S, et al. Effects of A3309, an Ileal Bile Acid Transporter Inhibitor, on Colonic Transit and Symptoms in Females With Functional Constipation. Am J Gastroenterol 2011;106:2154-64.

40 Bouras EP, Camilleri M, Burton DD, et al. Prucalopride accelerates gastrointestinal and colonic transit in patients with constipation without a rectal evacuation disorder.

Gastroenterology 2001;120:354-60.

41 Prather CM, Camilleri M, Zinsmeister AR, et al. Tegaserod accelerates orocecal transit in patients with constipation-predominant irritable bowel syndrome. Gastroenterology 2000;118:463-8.

42 Manabe N, Cremonini F, Camilleri M, et al. Effects of bisacodyl on ascending colon emptying and overall colonic transit in healthy volunteers. Alimentary Pharmacology \& Therapeutics 2009;30:930-6.

43 Miner P, Camilleri M, Burton D, et al. Prucalopride induces high amplitude propagated contractions in the colon of patients with chronic constipation: A randomized study. Neurogastroenterology and Motility 2015;27:86-.

44 Preston DM, Lennard-Jones JE. Pelvic motility and response to intraluminal bisacodyl in slow-transit constipation. Dig Dis Sci 1985;30:289-94.

45 Sweetser S, Busciglio IA, Camilleri M, et al. Effect of a chloride channel activator, lubiprostone, on colonic sensory and motor functions in healthy subjects. American Journal of Physiology - Gastrointestinal and Liver Physiology 2009;296:G295-G301.

46 Ford AC, Moayyedi P, Lacy BE, et al. American College of Gastroenterology Monograph on the Management of Irritable Bowel Syndrome and Chronic Idiopathic Constipation. Am J Gastroenterol 2014;109:S2-S26.

47 DiPalma JA, Cleveland MB, McGowan J, et al. A comparison of polyethylene glycol laxative and placebo for relief of constipation from constipating medications. South Med J 2007;100:1085-90.

48 DiPalma JA, Cleveland Mv, McGowan J, et al. A Randomized, Multicenter, PlaceboControlled Trial of Polyethylene Glycol Laxative for Chronic Treatment of Chronic Constipation. Am J Gastroenterol 2007;102:1436-41.

49 Corazziari E, Badiali D, Bazzocchi G, et al. Long term efficacy, safety, and tolerabilitity of low daily doses of isosmotic polyethylene glycol electrolyte balanced solution (PMF-100) in the treatment of functional chronic constipation. Gut 2000;46:522-6. 
50 Corazziari E, Badiali D, Habib FI, et al.. Small volume isosmotic polyethylene glycol electrolyte balanced solution (PMF-100) in treatment of chronic nonorganic constipation. Dig Dis Sci 1996;41:1636-42.

51 Cinca R, Chera D, Gruss HJ, et al. Randomised clinical trial: macrogol/PEG $3350+$ electrolytes versus prucalopride in the treatment of chronic constipation - a comparison in a controlled environment. Alimentary Pharmacology \& Therapeutics 2013;37:876-86.

52 Puhan MA, Schünemann HJ, Murad MH, et al. A GRADE Working Group approach for rating the quality of treatment effect estimates from network meta-analysis. BMJ 2014;349. 53 Bielefeldt K, Levinthal DJ, Nusrat S. Effective Constipation Treatment Changes More Than Bowel Frequency: A Systematic Review and Meta-Analysis. Journal of Neurogastroenterology and Motility 2016;22:31-45. 
Table 1. Study Characteristics

\begin{tabular}{|c|c|c|c|c|c|c|c|c|c|}
\hline Study ID & Location & Drug & $\begin{array}{l}\text { Doses } \\
\text { tested }\end{array}$ & $\begin{array}{l}\text { Study } \\
\text { Duration } \\
\text { (weeks) }\end{array}$ & $\begin{array}{l}\text { Number Total: } \\
\text { Intervention/ } \\
\text { control }\end{array}$ & Age (I) & Age (C) & $\begin{array}{l}\text { Gender, } \\
\text { F \% }\end{array}$ & Constipation criteria \\
\hline $\begin{array}{l}\text { Camilleri } \\
2008\end{array}$ & USA & PRU & $\begin{array}{l}2 \mathrm{mg} \\
4 \mathrm{mg} \mathrm{QD}\end{array}$ & 12 & 620: $411 / 209$ & $48.0 \pm 14.3$ & $48.9 \pm 13.0$ & 87.1 & $\begin{array}{l}\leq 2 \mathrm{CSBM} \text { /week for } 6 \text { months, and } \\
\text { Rome III criteria\# }\end{array}$ \\
\hline $\begin{array}{l}\text { Coremans } \\
2003\end{array}$ & Belgium & PRU & $4 \mathrm{mg}$ QD & 4 & 53: $27 / 26$ & $43.8 \pm 2.7$ & $47.4 \pm 2.9$ & 98.1 & $\begin{array}{l}\geq 2 \text { of the following for } 6 \text { months: } 2 \\
\text { SBM/week and Rome III criteria }{ }^{\#}\end{array}$ \\
\hline Ke 2012 & $\begin{array}{l}\text { Asia- } \\
\text { pacific }\end{array}$ & PRU & $2 \mathrm{mg} Q \mathrm{QD}$ & 12 & 501: $249 / 252$ & $\begin{array}{c}41.4 \pm 12.9 \\
2\end{array}$ & $41.8 \pm 12.9$ & 90 & $\begin{array}{l}\leq 2 \mathrm{SBM} / \text { week on average, and } \geq 1 \text { of } \\
\text { the following in Rome III criteria* }\end{array}$ \\
\hline $\begin{array}{l}\text { Mueller- } \\
\text { Lissner } 2010\end{array}$ & Int & PRU & $\begin{array}{l}1 \mathrm{mg} \\
2 \mathrm{mg} \\
4 \mathrm{mg} \text { QD }\end{array}$ & 4 & 300: $230 / 70$ & $76.5 \pm 7.7$ & $76 \pm 7.4$ & 70.3 & $\begin{array}{l}\leq 2 \mathrm{CSBM} / \text { week for } 6 \text { months and } \geq 1 \text { of } \\
\text { the following in Rome III criteria }{ }^{\#}\end{array}$ \\
\hline $\begin{array}{l}\text { Piessevaux } \\
2015\end{array}$ & Europe & PRU & $2 \mathrm{mg}$ QD & 24 & 346: $177 / 169$ & $49.4 \pm 15.8$ & $48.3 \pm 16.3$ & $14.7^{\$}$ & $\begin{array}{l}\leq 2 \mathrm{CSBM} / \text { week and } \geq 1 \text { of the } \\
\text { following in Rome III criteria\# for } 6 \\
\text { months }\end{array}$ \\
\hline $\begin{array}{l}\text { Quigley } \\
2009\end{array}$ & USA & PRU & $\begin{array}{l}2 \mathrm{mg} \\
4 \mathrm{mg} \text { QD }\end{array}$ & 12 & 641: 429/212 & $48.9 \pm 13.9$ & $46.2 \pm 13.0$ & 86.6 & $\begin{array}{l}\leq 2 \mathrm{CSBM} / \text { week for } 6 \text { months and } \geq 1 \text { of } \\
\text { the following in Rome III criteria }{ }^{\#} \text { for } 6 \\
\text { months }\end{array}$ \\
\hline Tack 2009 & Int & PRU & $\begin{array}{l}2 \mathrm{mg} \\
4 \mathrm{mg} \text { QD }\end{array}$ & 12 & 713: 473/240 & $44.1 \pm 15.1$ & $43.7 \pm 15.3$ & 90.8 & $\begin{array}{l}\leq 2 \mathrm{CSBM} / \text { week for } 6 \text { months and } \geq 1 \text { of } \\
\text { the following in Rome III criteria }{ }^{\#} \text { for } \\
6 \text { months }\end{array}$ \\
\hline $\begin{array}{l}\text { Emmanuel } \\
2002\end{array}$ & UK & PRU & $1 \mathrm{mg}$ QD & 4 & $74: 37 / 37$ & NA & NA & 100 & $\begin{array}{l}\leq 2 \mathrm{SBM} / \text { week and need to strain at } \\
\text { least } 25 \% \text { of the defecation. }\end{array}$ \\
\hline $\begin{array}{l}\text { Yiannnakou } \\
2015\end{array}$ & Europe & PRU & $2 \mathrm{mg}$ QD & 12 & 370: $184 / 186$ & $58.4 \pm 17.6$ & $58.5 \pm 16.3$ & $0^{\mathbb{I}}$ & $\begin{array}{l}\leq 2 \mathrm{CSBM} / \text { week for } 6 \text { months and } \geq 1 \text { of } \\
\text { the following in Rome III criteria }{ }^{\#} \text { for } \\
6 \text { months }\end{array}$ \\
\hline $\begin{array}{l}\text { Goldberg } \\
2010\end{array}$ & USA & VEL & $\begin{array}{l}15 \mathrm{mg} \\
30 \mathrm{mg} \\
45 \mathrm{mg} \\
\text { QD }\end{array}$ & 4 & 401: 294/107 & $44.4 \pm 11.7$ & $45.4 \pm 10.0$ & 92.0 & $\begin{array}{l}\geq 18 \text { years of age satisfying Rome } 3 \\
\text { criteria functional constipation* }\end{array}$ \\
\hline Fried 2007 & Int & TEG & $6 \mathrm{mg}$ bid & 12 & 322: $158 / 164$ & $51.1 \pm 17.1$ & $51.8 \pm 17.2$ & $0^{\mathrm{TI}}$ & $\begin{array}{l}\leq 3 \mathrm{CSBM} / \text { week and } \geq 1 \text { of the } \\
\text { following in Rome III criteria }{ }^{\#} \text { for } 6 \\
\text { months }\end{array}$ \\
\hline Kamm 2005 & Int & TEG & $\begin{array}{l}2 \mathrm{mg}, \\
6 \mathrm{mg} \text { bid }\end{array}$ & 12 & 1264: $848 / 416$ & $46.3 \pm 15.2$ & $46.0 \pm 15.6$ & 86.3 & $\begin{array}{l}\leq 3 \mathrm{CSBM} / \text { week and } \geq 1 \text { of the } \\
\text { following in Rome III criteria }{ }^{\#} \text { for } 6 \\
\text { months }\end{array}$ \\
\hline
\end{tabular}




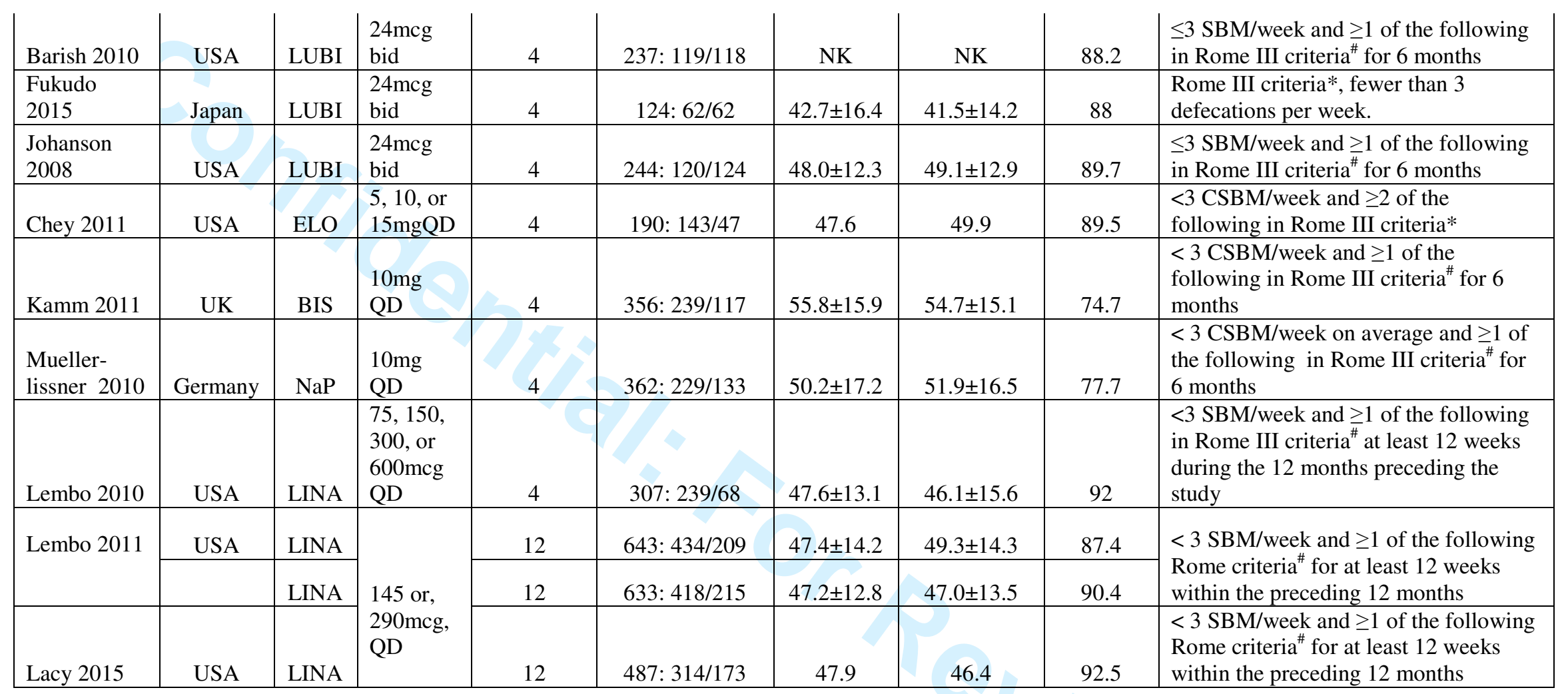

*- Rome III criteria which includes straining,

\# - Part of the Rome III criteria which includes $\geq 25 \%$ straining, incomplete evacuation and hard/lumpy stools,

$\$-85.32 \%$ were male, ${ }^{\mathbb{I}} 100 \%$ were men,

PRU- Prucalopride, VEL- Velusetrag, TEG- Tegaserod, LUBI- Lubiprostone, ELO- Elobixibat, BIS- Bisacodyl, NaP- Sodium Picosulphate, LINA- Linaclotide, MC- Multicenter, SC- Single center, Int- International, I- Intervention, C- Control. 
Table 2. Study Quality (CGR=computer generated randomization; $\mathrm{Rx}=$ intervention arm, $\mathrm{C}=\mathrm{control}$; LOCF=last observation carried forward; PRU=prucalopride, VEL=velusetrag, TEG=tegaserod, LUBI=lubiprostone, ELO=elobixibat, BIS=bisacodyl, NaP=sodium picosulphate, LINA=linaclotide)

\begin{tabular}{|c|c|c|c|c|c|c|c|}
\hline Study Identification & Drug & Generation of randomization sequence & $\begin{array}{l}\text { Allocation } \\
\text { concealment }\end{array}$ & $\begin{array}{l}\text { Double } \\
\text { Blind }\end{array}$ & $\begin{array}{l}\text { Lost to } \\
\text { follow up }\end{array}$ & $\begin{array}{l}\text { Methods used } \\
\text { for missing data }\end{array}$ & $\begin{array}{l}\text { Overall } \\
\text { Quality }\end{array}$ \\
\hline Camilleri 2008 & PRU & Consecutive numbering + block randomization of 3 & + & + & $5 \mathrm{Rx}, 3 \mathrm{C}$ & Imputation & High \\
\hline Coremans 2003 & PRU & Unclear & Unclear & + & 0 & - & Mod \\
\hline Ke 2012 & PRU & CGR & + & + & $3 \mathrm{Rx}, 2 \mathrm{C}$ & NS & Mod \\
\hline Mueller-Lissner 2010 & PRU & Randomization code generated by sponsor & + & + & 0 & $\begin{array}{l}\text { Considered as } \\
\text { non-responders }\end{array}$ & High \\
\hline Piessevaux 2015 & PRU & Randomization by web-based/voice-response system. & + & + & 0 & Imputation & Low \\
\hline Quigley 2009 & PRU & Block randomization of three & + & + & $5 \mathrm{Rx}, 2 \mathrm{C}$ & Imputation & High \\
\hline Tack 2009 & PRU & Random allocation sequence by the investigator & Unclear & + & $5 \mathrm{Rx}, 1 \mathrm{C}$ & $\begin{array}{l}\text { Considered as } \\
\text { non-responders }\end{array}$ & High \\
\hline Emmanuel 2002 & PRU & Method not known & Unclear & + & ORx, $1 \mathrm{C}$ & NS & Mod \\
\hline Yiannnakou 2015 & PRU & Central interactive web based response system & + & + & $2 \mathrm{Rx}, \mathrm{OC}$ & Imputation & Mod \\
\hline Goldberg 2010 & VEL & $\begin{array}{l}\text { Telephonic interactive voice response system using a } \\
\text { permuted block algorithm }\end{array}$ & + & + & NK & LOCF & High \\
\hline Fried 2007 & TEG & $\begin{array}{l}\text { Validated system that automated the random } \\
\text { assignment by sponsor }\end{array}$ & + & + & 0 & - & High \\
\hline Kamm 2005 & TEG & Randomized using validated computer system & + & + & $26 \mathrm{Rx}, 10 \mathrm{C}$ & NS & Mod \\
\hline Barish 2010 & LUBI & Block randomization of four & + & + & $4 \mathrm{Rx}, 1 \mathrm{C}$ & LOCF & Mod \\
\hline Fukudo 2015 & LUBI & Method not known & Unclear & + & 0 & - & Mod \\
\hline Johanson 2008 & LUBI & Block randomization of four & + & + & $1 \mathrm{Rx}, 2 \mathrm{C}$ & LOCF & Mod \\
\hline Chey 2011 & ELO & CGR by sponsor & + & + & $1 \mathrm{Rx}, 0 \mathrm{C}$ & NS & Mod \\
\hline Kamm 2011 & BIS & CGR & + & + & 0 & - & High \\
\hline Mueller-Lissner 2010 & $\mathrm{NaP}$ & CGR & + & + & 0 & & High \\
\hline Lembo 2010 & LINA & CGR using a block size of 5 & + & + & $3 \mathrm{Rx}, 0 \mathrm{C}$ & \multirow{2}{*}{$\begin{array}{l}\text { Observed-cases } \\
\text { approach }\end{array}$} & Mod \\
\hline Lembo 2011 & LINA & CGR using a block size of 6 & + & + & $29 \mathrm{Rx}, 4 \mathrm{C}$ & & High \\
\hline Lacy 2015 & LINA & $\begin{array}{l}\text { Randomization by statistical programmer not } \\
\text { involved in the trial }\end{array}$ & + & + & $10 \mathrm{Rx}, 5 \mathrm{C}$ & $\begin{array}{l}\text { Considered as } \\
\text { non-responders }\end{array}$ & High \\
\hline
\end{tabular}


Table 3. Pooled RR, and 95\% confidence intervals (for network meta-analysis) for primary endpoints (p<0.05 is bolded). (Note: For lubiprostone, both of the endpoints are not available $+=$ Superior, -=Inferior).

\section{A. Responders with $\geq 3$ CSBM per week for the drugs for CIC}

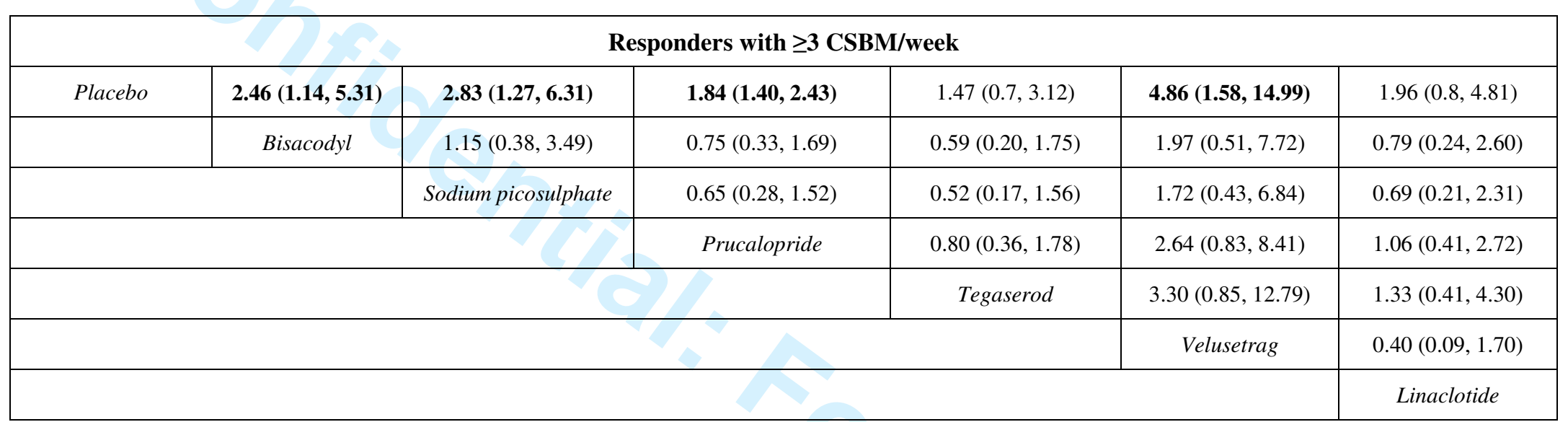

3B. Responders with $\geq 1$ CSBM per week for the drugs for CIC

\begin{tabular}{|c|c|c|c|c|c|c|c|}
\hline \multicolumn{8}{|c|}{ Responders with increase over baseline by $\geq 1$ CSBM/week } \\
\hline \multirow[t]{2}{*}{ Placebo } & $2.04(1.3,3.19)$ & $2.03(1.27,3.23)$ & $1.54(1.30,1.83)$ & $1.33(0.97,1.83)$ & $3.1(1.61,5.95)$ & $1.72(1.0,2.96)$ & $1.97(1.09,3.55)$ \\
\hline & Bisacodyl & $0.99(0.52,1.9)$ & $0.76(0.47,1.22)$ & $0.65(0.38,1.13)$ & $1.52(0.69,3.35)$ & $0.84(0.42,1.71)$ & $0.96(0.46,2.02)$ \\
\hline & & Sodium picosulphate & $0.76(0.46,1.25)$ & $0.66(0.37,1.16)$ & $1.53(0.69,3.41)$ & $0.85(0.42,1.74)$ & $0.97(0.46,2.06)$ \\
\hline & & & Prucalopride & $0.86(0.60,1.23)$ & $2.01(1.02,3.93)$ & $1.11(0.63,1.97)$ & $1.27(0.69,2.35)$ \\
\hline & & & & Tegaserod & $2.33(1.13,4.80)$ & $1.29(0.69,2.42)$ & $1.48(0.76,2.89)$ \\
\hline & & & & & Velusetrag & $0.56(0.24,1.30)$ & $0.64(0.26,1.53)$ \\
\hline & & & & & & Linaclotide & $1.14(0.51,2.55)$ \\
\hline & & & & & & & Elobixibat \\
\hline
\end{tabular}


Table 4. Pooled weighted mean difference, and $95 \%$ confidence intervals (for network meta-analysis) for Secondary endpoints ( $p<0.05$ is bolded). (Note: Tegaserod both of the endpoints are not available, $+=$ Superior, $-=$ Inferior).

4A. Number of CSBM change from baseline for the drugs for CIC

\begin{tabular}{|c|c|c|c|c|c|}
\hline \multicolumn{6}{|c|}{ \# of CSBM/week change from baseline } \\
\hline \multirow[t]{2}{*}{ Placebo } & $3.2(2.37,4.03)$ & $2.0(1.19,2.81)$ & $0.9(0.52,1.28)$ & $1.55(0.90,2.19)$ & $1.99(0.77,3.22)$ \\
\hline & Bisacodyl & $-1.2(-2.36,-0.04)$ & $-2.3(-3.22,-1.38)$ & $-1.65(-2.70,-0.60)$ & $-1.21(-2.69,-0.28)$ \\
\hline & & Sodium picosulphate & $-1.10(-1.99,-0.21)$ & $-0.45(-1.48,0.58)$ & $-0.01(-1.47,1.46)$ \\
\hline & & & Prucalopride & $0.65(-0.10,1.40)$ & $1.09(-0.19,2.38)$ \\
\hline & & & & Linaclotide & $0.44(-0.94,1.83)$ \\
\hline & & & & & Elobixibat \\
\hline
\end{tabular}

4B. Number of SBM change from baseline for the drugs for CIC

\begin{tabular}{|c|c|c|c|c|c|c|c|}
\hline \multicolumn{8}{|c|}{ \# of SBM/week change from baseline } \\
\hline \multirow[t]{8}{*}{ Placebo } & $4.9(3.90,5.90)$ & $3.20(2.28,4.12)$ & $1.93(1.45,2.40)$ & $2.07(1.12,3.01)$ & $2.13(1.54,2.71)$ & $2.08(0.76,3.41)$ & $1.93(1.30-2.55)$ \\
\hline & Bisacodyl & $-1.7(-3.05,-0.35)$ & $-2.97(-4.07,-1.87)$ & $-2.83(-4.20,-1.46)$ & $-2.77(-3.93,-1.62)$ & $-2.82(-4.48,-1.16)$ & $-2.97(-4.14--1.79)$ \\
\hline & & Sodium picosulphate & $-1.27(-2.30,-0.24)$ & $-1.13(-2.45,0.18)$ & $-1.07(-2.16,0.01)$ & $-1.12(-2.73,0.49)$ & $-1.27(-2.38--0.16)$ \\
\hline & & & Prucalopride & $0.14(-0.92,1.20)$ & $0.2(-0.55,0.95)$ & $0.15(-1.26,1.56)$ & $0(-0.79-0.79)$ \\
\hline & & & & Velusetrag & $0.06(-1.05,1.17)$ & $0.01(-1.61,1.64)$ & $-0.14(-1.27-0.99)$ \\
\hline & & & & & Linaclotide & $-0.04(-1.49,1.40)$ & $-0.2(-1.05-0.66)$ \\
\hline & & & & & & Elobixibat & $-0.15(-1.62-1.31)$ \\
\hline & & & & & & & Lubiprostone \\
\hline
\end{tabular}


Table 5. Quality of Evidence for Responders with $\geq 1$ CSBM

(\# -Inconsistency, \#\# -Severe inconsistency, \$ -Indirectness, \$ -Severe indirectness, * - Imprecision, **- Severe imprecision, ${ }^{\S}$-Risk of bias, p<0.05 is bolded)

\begin{tabular}{|c|c|c|c|c|c|c|}
\hline Comparison & Direct & Quality of evidence & Indirect & Quality of evidence & Network & Quality of evidence \\
\hline Bisacodyl v Placebo & $2.04(1.62,2.57)$ & High & - & - & $2.04(1.3,3.19)$ & High \\
\hline Na P v Placebo & $2.03(1.56,2.64)$ & High & - & - & $2.03(1.27,3.23)$ & High \\
\hline Prucalopride v Placebo & $1.54(1.28,1.86)$ & Moderate $^{\S}$ & - & - & $1.54(1.30,1.83)$ & Moderate $^{\S}$ \\
\hline Tegaserod v Placebo & $1.32(1.14,1.52)$ & High & - & - & $1.33(0.97,1.83)$ & High \\
\hline Velusetrag v Placebo & $3.1(1.83,5.24)$ & High & - & - & $3.1(1.61,5.95)$ & High \\
\hline Linaclotide v Placebo & $1.72(1.18,2.52)$ & High & - & - & $1.72(1.0,2.96)$ & High \\
\hline Elobixibat v Placebo & $1.97(1.26,3.07)$ & Moderate $^{\S}$ & - & - & $1.97(1.09,3.55)$ & Moderate $^{\S}$ \\
\hline Na P v Bisacodyl & - & - & $0.99(0.52,1.9)$ & High & $0.99(0.52,1.9)$ & Low** \\
\hline Prucalopride v Bisacodyl & - & - & $0.76(0.47,1.22)$ & Moderate & $0.76(0.47,1.22)$ & Very Low** \\
\hline Tegaserod v Bisacodyl & - & - & $0.65(0.38,1.13)$ & High & $0.65(0.38,1.13)$ & Low** \\
\hline Velusetrag v Bisacodyl & - & - & $1.52(0.69,3.35)$ & High & $1.52(0.69,3.35)$ & Low** \\
\hline Linaclotide v Bisacodyl & - & - & $0.84(0.42,1.71)$ & High & $0.84(0.42,1.71)$ & Low** \\
\hline Elobixibat v Bisacodyl & - & - & $0.96(0.46,2.02)$ & Moderate & $0.96(0.46,2.02)$ & Very Low** \\
\hline Prucalopride v Na P & - & - & $0.76(0.46,1.25)$ & Moderate & $0.76(0.46,1.25)$ & Very Low** \\
\hline Tegaserod v Na P & - & - & $0.66(0.37,1.16)$ & High & $0.66(0.37,1.16)$ & Low** \\
\hline Velusetrag v Na P & - & - & $1.53(0.69,3.41)$ & High & $1.53(0.69,3.41)$ & Low** \\
\hline Linaclotide $\mathrm{v} \mathrm{Na} \mathrm{P}$ & - & - & $0.85(0.42,1.74)$ & High & $0.85(0.42,1.74)$ & Low** \\
\hline Elobixibat v Na P & - & - & $0.97(0.46,2.06)$ & Moderate & $0.97(0.46,2.06)$ & Very Low** \\
\hline Tegaserod v Prucalopride & - & - & $0.86(0.60,1.23)$ & Moderate & $0.86(0.60,1.23)$ & Very Low** \\
\hline Velusetrag v Prucalopride & - & - & $2.01(1.02,3.93)$ & Moderate & $2.01(1.02,3.93)$ & Low* \\
\hline Linaclotide v Prucalopride & - & - & $1.11(0.63,1.97)$ & Moderate & $1.11(0.63,1.97)$ & Very Low** \\
\hline Elobixibat v Prucalopride & - & - & $1.27(0.69,2.35)$ & Moderate & $1.27(0.69,2.35)$ & Very Low** \\
\hline Velusetrag v Tegaserod & - & - & $2.33(1.13,4.80)$ & High & $2.33(1.13,4.80)$ & Moderate* \\
\hline Linaclotide v Tegaserod & - & - & $1.29(0.69,2.42)$ & High & $1.29(0.69,2.42)$ & Low** \\
\hline Elobixibat v Tegaserod & - & - & $1.48(0.76,2.89)$ & Moderate & $1.48(0.76,2.89)$ & Very Low** \\
\hline Linaclotide v Velusetrag & - & - & $0.56(0.24,1.30)$ & High & $0.56(0.24,1.30)$ & Low** \\
\hline Elobixibat v Velusetrag & - & - & $0.64(0.26,1.53)$ & Moderate & $0.64(0.26,1.53)$ & Very Low** \\
\hline Elobixibat v Linaclotide & - & - & $1.14(0.51,2.55)$ & Moderate & $1.14(0.51,2.55)$ & Very Low** \\
\hline
\end{tabular}


Table 6. Sensitivity analysis based on dose of medication (for primary endpoints NS if RR's 95\% CI overlaps 1, for secondary endpoints NS if RR's 95\% CI overlaps 0)

\begin{tabular}{|c|c|c|c|c|c|c|c|c|c|c|c|c|}
\hline \multirow[t]{2}{*}{ Drug } & \multicolumn{3}{|c|}{ Responders with $\geq 3$ CSBM } & \multicolumn{3}{|c|}{$\begin{array}{c}\text { Responders with increase over } \\
\text { baseline by } \geq \mathbf{1} \text { CSBM }\end{array}$} & \multicolumn{3}{|c|}{$\Delta \mathrm{b}$ CSBM/wk } & \multicolumn{3}{|c|}{$\Delta \mathrm{b}$ SBM/wk } \\
\hline & Standard & Low & High & Standard & Low & High & Standard & Low & High & Standard & Low & High \\
\hline $\begin{array}{l}\text { Bisacodyl v } \\
\text { Placebo }\end{array}$ & $\begin{array}{c}2.46 \\
(1.81 \\
3.35)\end{array}$ & 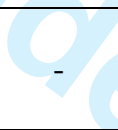 & - & $\begin{array}{c}2.04 \\
(1.62,2.57)\end{array}$ & - & - & $\begin{array}{c}3.2 \\
(2.66 \\
3.74)\end{array}$ & - & - & $\begin{array}{c}4.90 \\
(4.14 \\
5.66)\end{array}$ & - & - \\
\hline Na P v Placebo & $\begin{array}{r}2.83 \\
(1.93, \\
4.16) \\
\end{array}$ & - & - & $\begin{array}{c}2.03 \\
(1.56,2.64)\end{array}$ & - & - & $\begin{array}{c}2.0 \\
(1.51 \\
2.49) \\
\end{array}$ & - & - & $\begin{array}{r}3.20 \\
(2.55 \\
3.85) \\
\end{array}$ & - & - \\
\hline $\begin{array}{l}\text { Prucalopride v } \\
\text { Placebo }\end{array}$ & $\begin{array}{c}2.04 \\
(1.59 \\
2.62)\end{array}$ & $\begin{array}{l}1.31 \\
(0.56, \\
3.04)\end{array}$ & $\begin{array}{c}2.23 \\
(1.74, \\
2.85)\end{array}$ & $\begin{array}{c}1.54 \\
(1.24,1.92)\end{array}$ & $\begin{array}{l}1.81 \\
(1.23, \\
2.66)\end{array}$ & $\begin{array}{l}1.71 \\
(1.45 \\
2.01)\end{array}$ & $\begin{array}{c}0.88 \\
(0.49 \\
1.28)\end{array}$ & $\begin{array}{c}1.30 \\
(0.76, \\
1.84)\end{array}$ & $\begin{array}{c}0.9 \\
(0.42 \\
1.38)\end{array}$ & $\begin{array}{r}1.58 \\
(0.72, \\
2.44)\end{array}$ & $\begin{array}{c}1.85 \\
(0.79 \\
2.91)\end{array}$ & $\begin{array}{r}1.63 \\
(0.46 \\
2.81)\end{array}$ \\
\hline $\begin{array}{l}\text { Tegaserod v } \\
\text { Placebo }\end{array}$ & $\begin{array}{l}1.75 \\
(1.32, \\
2.33)\end{array}$ & $\begin{array}{c}1.18 \\
(0.86, \\
1.62)\end{array}$ & - & $\begin{array}{c}1.41 \\
(1.18,1.69)\end{array}$ & $\begin{array}{r}1.17 \\
(0.96, \\
1.42)\end{array}$ & - & - & - & - & - & - & - \\
\hline $\begin{array}{l}\text { Velusetrag v } \\
\text { Placebo }\end{array}$ & $\begin{array}{c}4.09 \\
(1.59 \\
10.51)\end{array}$ & $\begin{array}{c}5.57 \\
(2.24 \\
13.86)\end{array}$ & $\begin{array}{c}4.9 \\
(1.93, \\
12.43)\end{array}$ & $\begin{array}{c}2.49 \\
(1.38,4.46)\end{array}$ & $\begin{array}{c}3.33 \\
(1.91, \\
5.80)\end{array}$ & $\begin{array}{c}3.5 \\
(2.01 \\
6.10)\end{array}$ & & & - & $\begin{array}{r}1.90 \\
(1.23, \\
2.57)\end{array}$ & $\begin{array}{l}2.20 \\
(1.55 \\
2.85)\end{array}$ & $\begin{array}{r}2.10 \\
(1.35 \\
2.85)\end{array}$ \\
\hline $\begin{array}{l}\text { Linaclotide v } \\
\text { Placebo }\end{array}$ & $\begin{array}{r}1.92 \\
(1.03, \\
3.57)\end{array}$ & - & $\begin{array}{c}2.0 \\
(1.08, \\
3.69)\end{array}$ & $\begin{array}{c}1.64 \\
(1.07,2.51)\end{array}$ & - & $\begin{array}{c}1.81 \\
(1.19 \\
2.73)\end{array}$ & $\begin{array}{l}1.45 \\
(1.09 \\
1.82)\end{array}$ & $\begin{array}{l}1.02 \\
(0.22, \\
1.82)\end{array}$ & $\begin{array}{l}1.70 \\
(1.39, \\
2.01)\end{array}$ & $\begin{array}{c}1.83 \\
(1.18 \\
2.48)\end{array}$ & - & $\begin{array}{r}2.26 \\
(1.84 \\
2.68)\end{array}$ \\
\hline $\begin{array}{l}\text { Elobixibat v } \\
\text { Placebo }\end{array}$ & - & - & - & $\begin{array}{c}2.25 \\
(1.42,3.58)\end{array}$ & $\begin{array}{c}1.74 \\
(1.06, \\
2.87)\end{array}$ & $\begin{array}{l}2.25 \\
(1.42 \\
3.58)\end{array}$ & $\begin{array}{l}1.46 \\
(0.54, \\
2.38)\end{array}$ & $\begin{array}{r}1.42 \\
(0.25 \\
2.59)\end{array}$ & $\begin{array}{c}3.09 \\
(2.05 \\
4.13)\end{array}$ & $\begin{array}{r}1.79 \\
(0.72 \\
2.86)\end{array}$ & $\begin{array}{c}1.18 \\
(-0.06 \\
2.42)\end{array}$ & $\begin{array}{r}3.27 \\
(2.11 \\
4.43)\end{array}$ \\
\hline $\begin{array}{l}\text { Lubiprostone } \mathbf{v} \\
\text { placebo }\end{array}$ & - & - & - & - & - & - & - & - & - & $\begin{array}{r}1.92 \\
(1.35 \\
2.49)\end{array}$ & - & - \\
\hline
\end{tabular}


Drug: Standard dose, Low dose, High dose. Prucalopride: 2mg QD, 1 mg QD, 4mg QD.

Velusetrag: 30mg QD, 15mg QD, 50mg QD. Tegaserod: 6mg bid, 2mg bid, no high dose.

Linaclotide: 145/150mcg QD, 75mcg QD, 290/600mcg QD.

Elobixibat: 10mg QD, 5mg QD, $15 \mathrm{mg}$ QD. Lubiprostone: $24 \mathrm{mcg}$ bid, no low and high dose. 
Nelson, Camilleri, et al. - 33 -

\section{FIGURE LEGENDS}

Figure 1: Flow diagram of included studies identified for systematic review.

Figure 2: Network diagram (CT=clinical trials, $\mathrm{P}=$ patients)

Figure 3: Comparisons between treatment vs. placebo of primary endpoints, $\geq 3 \mathrm{CSBM} /$ week (panel A) or increase over baseline by >1 CSBM/week (panel B), and secondary endpoints, change in CSBM from baseline (panel C) and change in SBM from baseline (panel D). 
Figure 1. Flow diagram of included studies identified for systematic review. $254 \times 190 \mathrm{~mm}(300 \times 300 \mathrm{DPI})$ 


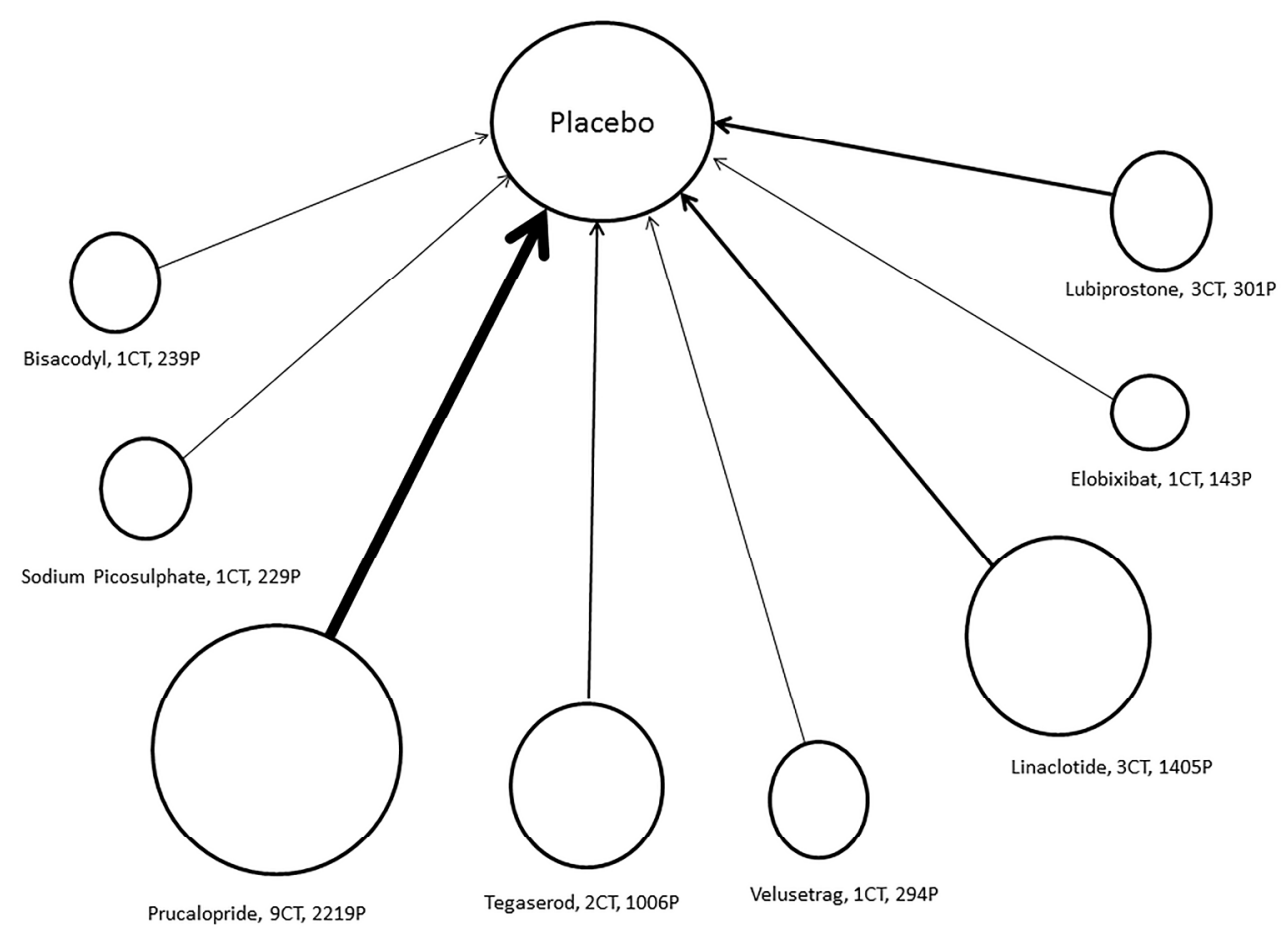

Figure 2. Network diagram ( $\mathrm{CT}=$ clinical trials, $\mathrm{P}=$ patients) $254 \times 190 \mathrm{~mm}$ (300 x 300 DPI) 
Figure $3 A$. Comparisons between treatment vs. placebo of primary endpoints, $\geq 3$ CSBM/week (panel A) or increase over baseline by $>1$ CSBM/week (panel B), and secondary endpoints, change in CSBM from baseline (panel C) and change in SBM from baseline (panel D). $254 \times 190 \mathrm{~mm}(300 \times 300 \mathrm{DPI})$ 
Figure 3B. Comparisons between treatment vs. placebo of primary endpoints, $\geq 3$ CSBM/week (panel A) or increase over baseline by $>1$ CSBM/week (panel B), and secondary endpoints, change in CSBM from baseline (panel $C$ ) and change in SBM from baseline (panel D). $254 \times 190 \mathrm{~mm}(300 \times 300 \mathrm{DPI})$ 
Figure 3C. Comparisons between treatment vs. placebo of primary endpoints, $\geq 3$ CSBM/week (panel A) or increase over baseline by $>1$ CSBM/week (panel B), and secondary endpoints, change in CSBM from baseline (panel C) and change in SBM from baseline (panel D). $254 \times 190 \mathrm{~mm}(300 \times 300 \mathrm{DPI})$ 
Figure 3D. Comparisons between treatment vs. placebo of primary endpoints, $\geq 3$ CSBM/week (panel A) or increase over baseline by $>1$ CSBM/week (panel B), and secondary endpoints, change in CSBM from baseline (panel C) and change in SBM from baseline (panel D). $254 \times 190 \mathrm{~mm}(300 \times 300 \mathrm{DPI})$ 


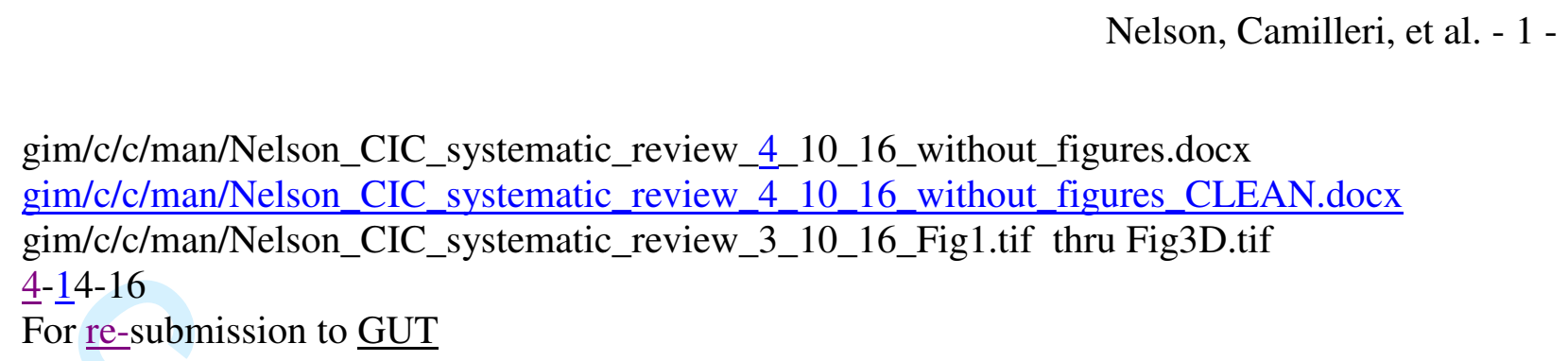

\title{
Comparison of Efficacy of Pharmacological Treatments for Chronic Idiopathic Constipation: A Systematic Review and Network Meta-analysis
}

\author{
Alfred D. Nelson, M.B.B.S. \\ Michael Camilleri, M.D. \\ Sakkarin Chirapongsathorn, M.D., M.Sc. \\ Priya Vijayvargiya, M.D. \\ Nelson Valentin, B.S. \\ Andrea Shin, M.D., M.Sc.* \\ Patricia J. Erwin \\ Zhen Wang, Ph.D." \\ M. Hassan Murad, M.D."
}

From

Clinical Enteric Neuroscience Translational and Epidemiological Research (CENTER) and "Mayo Clinic Evidence-Based Practice Center, Mayo Clinic, Rochester, MN 55905 *Dr. Shin's current affiliation: Indiana University, Indianapolis, IN

\begin{abstract}
Running title: Network meta-analysis of pharmacological agents for treatment of CIC
Word count: 3745 (excluding abstract, summary box, acknowledgements, disclosures, references, table and figure legends)
\end{abstract}

Key words: bisacodyl, elobixibat, linaclotide, lubiprostone, picosulfate, polyethylene glycol, prucalopride, tegaserod, velusetrag

Abbreviations:

chronic idiopathic constipation (CIC)

numbers needed to treat (NNT)

sodium picosulfate $(\mathrm{NaP})$

polyethylene glycol (PEG)

complete spontaneous bowel movements (CSBM)

spontaneous bowel movements (SBM)

weighted mean difference (WMD)

$\underline{\text { confidence interval }(\mathrm{CI})}$ 
Nelson, Camilleri, et al. - 2 -

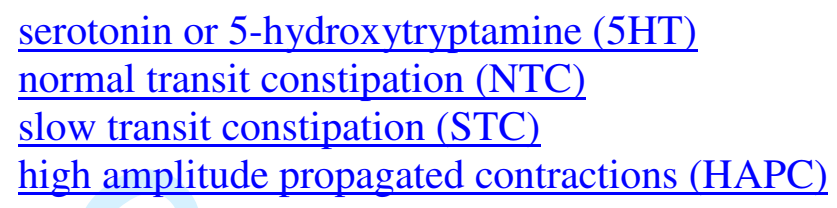

Address for correspondence: $\quad$ Michael Camilleri, M.D.

Mayo Clinic

200 First St. S.W.

Charlton Bldg., Rm. 8-110

Rochester, MN 55905

Tele: 507-266-2305

Email: camilleri.michael@mayo.edu 
Nelson, Camilleri, et al. - 3 -

\begin{abstract}
Objective: To compare efficacy of pharmacotherapies for chronic idiopathic constipation (CIC) based on comparisons to placebo using Bayesian network meta-analysis.

Data Sources: We conducted searches (inception to May 2015) of MEDLINE, EMBASE, Scopus and Cochrane Central, as well as original data from authors or drug companies for the medications used for CIC.

Study Selection: Phase IIB and phase III randomized, placebo-controlled trials (RCT) of $\geq 4$ weeks' treatment for CIC in adults with Rome II or III criteria for functional constipation; trials included at least 1 of 4 endpoints.
\end{abstract}

Data Extraction and Synthesis: Two investigators independently evaluated all full text articles that met inclusion criteria and extracted data for primary and secondary endpoints, risk of bias and quality of evidence.

Outcomes: Primary endpoints were $\geq 3$ complete spontaneous bowel movements (CSBM)/week and increase over baseline by $\geq 1 \mathrm{CSBM} /$ week. Secondary endpoints were change from baseline $\left(\Delta_{b}\right)$ in the number of SBM/week and $\Delta_{b}$ CSBM/week.

Results: Twenty-one RCTs (9189 patients) met inclusion and endpoint criteria: 9 prucalopride, 3 lubiprostone, 3 linaclotide, 2 tegaserod, 1 each velusetrag, elobixibat, bisacodyl and sodium picosulphate $(\mathrm{NaP})$. All pre-specified endpoints were unavailable in 4 polyethylene glycol studies. Bisacodyl, NaP, prucalopride and velusetrag were superior to placebo for the $\geq 3$ CSBM/week endpoint. No drug was superior at improving the primary endpoints on network meta-analysis. Bisacodyl appeared superior to the other drugs for the secondary endpoint, $\Delta_{b}$ in number of SBM/week. 
1

2

3

4

5

6

7

8

9

10

11

12

13

14

15

16

17

18

19

20

21

22

23

24

25

26

27

28

29

30

31

32

33

34

35

36

37

38

39

40

41

42

43

44

45

46

47

48

49

50

51

52

53

54

55

56

57

58

59

60
Nelson, Camilleri, et al. - 4 -

Conclusions: Current drugs for CIC show similar efficacy. Bisacodyl may be superior to prescription medications for $\Delta_{\mathrm{b}}$ in the number of SBM/week in CIC. 
Nelson, Camilleri, et al. - 5 -

\section{SUMMARY BOX}

What is already known about this subject?

- Fifty percent of patients with chronic idiopathic constipation (CIC) are not completely satisfied with treatment, especially with fiber and laxatives.

- The number needed to treat (NNT), estimated from placebo-controlled clinical trials in CIC comparing pharmacological therapies to placebo, have been reported as follows: osmotic and stimulant laxative, NNT 3; lubiprostone, NNT 4; and prucalopride and linaclotide, both NNT 6.

- The absence of direct comparisons between different drug classes limits comparison of efficacy among treatments.

\section{What are the new findings?}

- Current drugs for CIC show similar efficacy for primary endpoints, which were $\geq 3$ complete spontaneous bowel movements (CSBM)/week and increase over baseline by $\geq 1 \mathrm{CSBM} /$ week.

- Bisacodyl may be superior to prescription medications for change from baseline $(\Delta b)$ $\mathrm{SBM} /$ week in CIC and in comparison with some of the drugs in $\triangle \mathrm{b} \mathrm{CSBM} /$ week.

\section{How might it impact on clinical practice in the foreseeable future?}

- Head-to-head trials of active agents are necessary to determine the optimal selection of pharmacological agents for CIC.

- Alternatively, first line medications for patients with CIC should be according to the pathophysiology in order to increase efficacy, such as prokinetics for patients with documented slow transit constipation in the absence of rectal evacuation disorders. 
Nelson, Camilleri, et al. - 6 -

\section{INTRODUCTION}

The estimated global prevalence of chronic idiopathic constipation (CIC) in adults is 14\%.[1] It is usually diagnosed using Rome III symptom criteria,[2] is about twice as common in women and more prevalent over 65 years of age, significantly impacts quality of life, and constitutes a significant financial burden.[3] Treatment of constipation [4] usually starts with nonpharmacological agents like fiber (soluble in preference to nonsoluble fiber and is followed by pharmacological agents if there is no response to fiber.[5] Polyethylene glycol, an osmotic laxative, increases the mean number of stools per week more effectively than placebo or lactulose in adults with CIC, based on direct meta-analyses.[6] It is estimated that about 50\% of patients with CIC were not completely satisfied with treatment due to lack of efficacy or safety concerns, especially with fiber and laxatives (both stimulant and osmotic).

Therefore, this appraisal of the relative efficacy of pharmacotherapies for chronic CIC is clinically relevant. The pharmacological classes of the medications used for CIC are: diphenyl methanes or derivatives (bisacodyl and sodium picosulphate), 5- $\mathrm{HT}_{4}$ receptor agonists (prucalopride, tegaserod and velusetrag), guanylate cyclase $\mathrm{C}$ receptor agonist (linaclotide), chloride channel type 2 opener (lubiprostone) and apical sodium bile acid, (also known as ileal bile acid transport) inhibitor (elobixibat).

The numbers needed to treat (NNT), estimated from placebo-controlled clinical trials comparing these medications to placebo in CIC, were reported as follows: osmotic and stimulant laxative, NNT 3; lubiprostone, NNT 4; and prucalopride and linaclotide, both NNT 6.[6] This might suggest differences in efficacy of the different drug classes; however, this assessment was based on failure to respond to therapy, and vastly different endpoints were used in individual studies. 
Nelson, Camilleri, et al. - 7 -

The absence of direct comparisons between different drug classes limits comparison of efficacy among treatments to the endpoints currently recommended by the US Food and Drug Administration and is consistent with those of European Medicines Agency.[7] Therefore, our aim was to compare the efficacy of drugs for CIC based on results of each drug compared to placebo using Bayesian network meta-analysis and endpoints consistent with current regulatory agency recommendations.

\section{METHODS}

This systematic review and network meta-analysis was performed according to guidance provided by the Cochrane Handbook for Systematic Reviews of Interventions [8]. It is reported according to the Preferred Reporting Items for Systematic Reviews and Meta-Analyses (PRISMA) guidelines[9]. We followed an a priori established protocol.

\section{Search Methods for Identification of Studies}

A thorough database search was done in May 2015, using Ovid MEDLINE In-Process \& Other Non-Indexed Citations and Ovid MEDLINE (1946 to present), Ovid EMBASE, Scopus databases (1988 to 2015) and Ovid Cochrane CENTRAL (to March 2015) for all the drugs used for treatment of CIC. An expert librarian (PE) conducted the medical literature search with input from the investigators. All the studies for this meta-analysis were identified using a combination of subject headings and free text terms including constipation, chronic constipation, functional constipation, lubiprostone, linaclotide, plecanatide, bisacodyl, sodium picosulfate (NaP), prucalopride, velusetrag, naronapride, polyethylene glycol (PEG), lactulose, elobixibat, fiber, and randomized placebo-controlled trial. Terms were searched in the title, abstract, original title, name of substance word, subject heading word, keyword heading word, protocol supplementary concept word, rare disease supplementary concept word, and unique identifier. The search was 
Nelson, Camilleri, et al. - 8 -

conducted using combinations of these terms by using “and/or". Multiple different combinations of these terms were used. All the abstracts identified using the search strategy were independently evaluated by two investigators (AN and NV) in order to select studies that were eligible for inclusion. For those studies, full text articles were requested. Additional studies were added after review of these drugs in the treatment of CIC in clinicaltrials.gov and manual review of the citations in the publications. All the studies were independently identified by two investigators using well-defined inclusion criteria; conflicts were resolved by consensus between the two investigators after discussing with a third investigator (MC) with content expertise.

\section{Inclusion Criteria}

This systematic review and network meta-analysis was limited only to randomized, placebo-controlled trials of drugs that are either approved by FDA for CIC or drugs with data available for at least one pre-specified endpoint from phase IIB or III randomized, placebocontrolled trials, and $>4$ weeks of treatment. Participants included were adults ( $>18$ years of age) who satisfied Rome II or Rome III criteria for (chronic) functional constipation.

There were no exclusions based on gender, sample size, medical condition, language limitation or medications that are known to affect colonic transit or minimum follow-up period. All eligible studies were required to have placebo as control intervention.

\section{Outcome Assessment}

The current recommended endpoint required by regulatory agencies (specifically, the U.S. Food and Drug Administration) for demonstration of efficacy in CIC trials is $\geq 3$ complete spontaneous bowel movements (CSBM)/week and increase over baseline by $\geq 1 \mathrm{CSBM} /$ week in 9 out of 12 weeks of treatment. However, only randomized, placebo-controlled trials of linaclotide included this endpoint; therefore, we analyzed different endpoints that addressed 
Nelson, Camilleri, et al. - 9 -

similar outcomes, in order to be consistent in appraising efficacy among studies. The primary endpoints were the proportion of responders, based on $\geq 3 \mathrm{CSBM}$ )/week or the proportion of responders with increase over baseline by $\geq 1 \mathrm{CSBM} /$ week. The secondary endpoints were continuous, quantitative variables: the change from baseline $(\Delta \mathrm{b})$ in the number of spontaneous bowel movements (SBM)/week and $\triangle \mathrm{b}$ CSBM/week. Unfortunately, none of the four available PEG trials included the endpoints selected for our network meta-analysis.

\section{Data Extraction and Management}

Data extraction from the eligible studies was performed by two independent investigators (AN and SC) for the primary and secondary endpoints. Authors of the original publications were contacted by email or by phone requesting missing data in the eligible studies. Data were extracted from manuscripts or databases provided by the investigators or drug companies. Data for primary endpoints were extracted as number of responders and non-responders for each primary endpoint and mean and standard deviation for secondary endpoints.

We also collected data about characteristics of the randomized, placebo-controlled trials, such as study center location (by continents); total number, age and gender of participants in the intervention and control groups; type of intervention; duration of therapy; and criteria for a diagnosis of constipation. Finally, data were extracted to appraise study quality, such as method used for analysis of missing data and loss of follow-up in the intervention and control groups.

\section{Statistical Analysis}

We calculated relative risk for dichotomized outcomes, weighted mean difference (WMD) for continuous outcomes, and related confidence intervals. We performed head-to-head comparisons using DerSimonian-Laird random-effects model. We assessed statistical heterogeneity using the $\mathrm{I}^{2}$ statistic, which represents the proportion of heterogeneity that is not 
the result of chance, but reflects true differences across study populations and interventions; $\mathrm{I}^{2}$ $>50 \%$ indicates substantial heterogeneity. Direct comparisons were performed using RevMan v5.3 (The Nordic Cochrane Centre Copenhagen, Denmark).

Network meta-analyses were used to combine effect sizes for all possible comparisons (direct and indirect), regardless of whether they had been compared in trials. In contrast to traditional meta-analyses, which compare one intervention with another one at a time and combine evidence directly from head-to-head clinical trials (if such trials exist), the network meta-analyses allow comparison of all interventions simultaneously. A multivariate metaregression model developed by White was used.[10] The network meta-analyses were conducted using the "network" suite in Stata Version 14.0 (StataCorp LP, College Station, TX, USA).[10]

\section{Sensitivity Analysis}

We examined the effects of the drugs for CIC based on relative risks of the primary and secondary endpoints. We evaluated effect sizes based on therapeutic dose (standard dose group versus high dose) and study quality for prucalopride (low risk of bias versus high risk of bias) for CIC treatment. We also applied the "leave-one-out" method by excluding one study of 24 weeks duration to evaluate the robustness of our findings.

\section{Assessment of Risk of Bias and Publication Bias}

Risk of bias was assessed using Cochrane Handbook for Assessing the Risk of Bias [9]. Two investigators (AN and PV) independently assessed the randomization schedule, allocation concealment, blinding of participants and investigators, blinding of outcome assessment, methods used for missing data, selective reporting, incomplete outcome data, risk of bias for primary and secondary endpoints, and loss of follow up during the treatment period. Due to the 
Nelson, Camilleri, et al. - 11 -

limited number of studies included in the analyses, we were not able to evaluate potential publication bias.[11]

Quality of Evidence

We used the Grading of Recommendation, Assessment, Development and Evaluation (GRADE) Approach to rate the quality of evidence for the estimates derived from the network meta-analyses.[12] Since the studies included were only randomized, placebo-controlled trials, the quality of evidence was considered high in the beginning and down rated based on the assessment of risk of bias, inconsistency, indirectness, imprecision and publication bias. The quality of evidence is rated as high, moderate, low and very low. For indirect estimates, the rating usually starts at lowest rating of contributing direct evidence and can be further down rated based on imprecision and indirectness (mainly intransitivity, i.e., difference in patient populations between studies involved).

\section{RESULTS}

\section{Search Results}

The search strategy used identified 546 citations and, among these, we identified 114 articles for review for the full text appraisal. Among the 114 articles, only 18 articles met the inclusion criteria; 96 studies did not meet the inclusion criteria, most often because the endpoints in the trials were different from the selected primary and secondary endpoints, articles did not have original data, or they were nonrandomized studies. The agreement between the investigators (AN and NV) for selection of studies after full text review was high (Kappa statistic $0.86)$.

Three studies which were not identified by the search strategy were added by the investigators. We contacted the authors and drug sponsors of these studies for additional 
information regarding the primary and secondary endpoints, and their responses were added to the analysis.

Figure 1 shows the schematic diagram of study selection for the systematic review and meta-analysis; in total, 21 studies were eligible. The study characteristics are summarized in Table 1.

There were 9189 patients in the 21 studies: 9 with prucalopride, $[13,14,15,16,17,18$, 19, 20, 21] 3 with lubiprostone,[22, 23, 24] 3 with linaclotide,[25, 26, 27] 2 with tegaserod,[28, 29] 1 each with Velusetrag,[30] Elobixibat,[31] bisacodyl,[32] and sodium (Na) picosulphate.[33] The number of drugs, sample size of each drug, and the number of clinical trials included in the network meta-analysis are represented in the form of a network diagram (Figure 2).

The risk of bias of the included studies is summarized in Table 2. Overall, quality was high in 11 , moderate in 9 , and low in 1 study. Downgrading of quality was based most often on unstated details regarding blinding, allocation concealment or management of missing data.

\section{Direct Meta-analysis}

The results of the direct meta-analysis for each primary and secondary endpoint are summarized in Figure 3A-D.

\section{Primary Endpoints}

The data for responder analysis with $\geq 3 \mathrm{CSBM}$ /week were available for 14 randomized, placebo-controlled trials. All six drugs showed a significant increase in $\geq 3 \mathrm{CSBM} /$ week when compared to placebo. Among the three $5 \mathrm{HT}_{4}$ agonists (prucalopride, velusetrag and tegaserod), prucalopride showed higher efficacy [relative risk (RR)] of 1.85 with a $95 \%$ confidence interval (CI) of 1.35 to 2.54 when compared to placebo and with significant heterogeneity of $80.8 \%$ 
Nelson, Camilleri, et al. - 13 -

( $\mathrm{p}=0.0001)$. Velusetrag had an RR of $4.86(95 \% \mathrm{CI}, 2.02$ to 11.71$)$; the wider confidence interval may suggest velusetrag might be less efficacious, was considered inferiorwhen compared to prucalopride-since the $\mathrm{CI}$ is wide. Stimulant laxatives, bisacodyl and $\mathrm{NaP}$, showed approximately similar efficacy. For linaclotide, RR was 1.96 (95\% CI, 1.12 to 3.44). There was significant heterogeneity between studies of all the drugs appraised using this endpoint $\left(\mathrm{I}^{2}=77.4 \% \mathrm{P}<\right.$ $0.00001)$.

For responder analysis with increase over baseline by $\geq 1 \mathrm{CSBM} /$ week, data were available for 15 randomized, placebo-controlled trials; all 7 of the drugs were superior to placebo. Stimulant laxatives (bisacodyl and $\mathrm{NaP}$ ) and elobixibat showed approximately similar efficacy. Prucalopride showed superior efficacy among the $5 \mathrm{HT}_{4}$ agonists, but the heterogeneity between studies was significant $\left(\mathrm{I}^{2}=74.5 \%, \mathrm{p}=0.0001\right)$. Even though the RR for velusetrag was 3.10, which is relatively high when compared to the RR for prucalopride, the $95 \%$ CI with velusetrag was wide (1.83 to 5.24) and overlapped that of prucalopride. Given the overlapping $95 \%$ CI for the two drugs and the significant heterogeneity in the efficacy of prucalopride, the data show overall similar efficacy for prucalopride and velusetrag.

\section{Secondary Endpoints}

Data for $\underline{\Delta}_{\mathrm{b}} \underline{\mathrm{CSBM} / \text { week }}$ were available only for 5 drugs. All the drugs showed superior efficacy when compared to placebo. Bisacodyl had a weighted mean difference (WMD) of 3.20 (95\% CI, 2.66 to 3.74). Elobixibat and NaP had similar efficacy. For linaclotide, the WMD was 1.57, with heterogeneity $\mathrm{I}^{2}$ of $0 \%$; this WMD was greater than that of prucalopride which was 0.90 and was also associated with significant heterogeneity $\mathrm{I}^{2}$ of $76.8 \%$.

For the $\underline{\Delta}_{\underline{b}} \underline{S} \underline{\mathrm{SBM} / \text { week}}$, all 7 of the drugs showed superior efficacy relative to placebo. Bisacodyl showed higher efficacy with a WMD of 4.90 when compared to NaP (3.20). 
Velusetrag, elobixibat and linaclotide showed similar efficacy with a mean difference (MD) in the absolute number of $\underline{\Delta}_{\mathrm{b}} \underline{\mathrm{SBM}}$ /week of $\sim 2.08$. For prucalopride, the WMD was 2.03 , with significant heterogeneity of $63.9 \%$. For lubiprostone, WMD was 1.91 with an $\mathrm{I}^{2}$ of $23.4 \%$.

\section{Network Meta-analysis}

$\underline{\text { Responder analysis for } \geq 3 \text { CSBM/week (Table } 3 A \text { ) }}$

Except for tegaserod, all the other drugs (bisacodyl, NaP, prucalopride, velusetrag, linaclotide and elobixibat) showed superior efficacy compared to placebo, but none of the drugs showed superior efficacy when compared to each other in the network meta-analysis.

\section{$\underline{\text { Responder analysis for increase over baseline by } \geq 1 \text { CSBM/week (Table 3B) }}$}

Apart from tegaserod and linaclotide, all the drugs (bisacodyl, NaP, prucalopride and velusetrag) showed superior efficacy when compared to placebo, but none of the drugs showed superior efficacy when compared to each other in the network meta-analysis, with the exception of velusetrag which appears superior when compared to prucalopride and tegaserod.

\section{Change in number of CSBM/week compared to baseline (Table 4A)}

Bisacodyl, NaP, prucalopride, linaclotide and elobixibat showed superior efficacy on the $\Delta_{\mathrm{b}} \mathrm{CSBM}$ /week when compared to placebo. On a network meta-analysis, bisacodyl was superior to NaP, prucalopride and linaclotide. Bisacodyl did not show significant efficacy over elobixibat using this endpoint. NaP showed superior efficacy when compared to prucalopride.

\section{Change in number of SBM/week compared to baseline (Table 4B)}

When compared to placebo on a network meta-analysis, bisacodyl, $\mathrm{NaP}$, prucalopride, velusetrag, linaclotide, elobixibat and lubiprostone treatment showed superior increase in $\Delta_{\mathrm{b}} \mathrm{SBM} /$ week. 
Nelson, Camilleri, et al. - 15 -

Network meta-analysis suggested that bisacodyl is superior when $\mathrm{NaP}$, prucalopride, velusetrag, linaclotide, elobixibat and lubiprostone are compared to bisacodyl. NaP showed superior efficacy when prucalopride and lubiprostone were compared to $\mathrm{NaP}$.

\section{Quality of Evidence}

We applied the GRADE approach to the main outcome of $\geq 1 \mathrm{CSBM} /$ week because it had the largest number of included trials. In terms of direct estimates of drugs compared to placebo, the quality of evidence was moderate or high for all comparisons. However, most head-to-head comparisons were imprecise (i.e., their CIs were wide and overlapped the null effect). Therefore, the quality of evidence of head-to-head comparisons was mostly low (Table 5).

\section{Sensitivity Analysis}

We conducted sensitivity analyses based on dose of medication (for all drugs for which at least two doses were studied) and risk of bias (for prucalopride). Results were consistent between standard therapeutic dose group compared to high and low dose groups for the primary endpoints and for most of the secondary endpoint analyses (Table 6). An exception was that low dose (in contrast to standard or high dose) prucalopride was not effective compared to placebo for the endpoints of $\geqq 3 \mathrm{CSBM} /$ week and $\Delta \mathrm{b}$ SBM/week.

When analysis was restricted to prucalopride studies at low risk of bias, four trials[13, 16, $18,19]$ were included and, for the two primary responder analyses, we noted that for $\geq 3 \mathrm{CSBM} /$ week, the RR was $2.12(1.71,2.63)$ and, for increase over baseline by $\geq 1$ CSBM/week, the RR was $1.76(1.54,2.02)$; both had heterogeneity of $0 \%$.

A third sensitivity analysis assessed whether any one study with a markedly different duration [17] had a dominant effect on the pooled RR or heterogeneity. We found that this single study did not markedly affect the summary estimate for the prucalopride studies. Thus, including 
the study resulted in RRs for $\geq 3 \mathrm{CSBM} /$ week and for increase over baseline by $\geq 1 \mathrm{CSBM} /$ week of $1.85\left(\mathrm{I}^{2} 80.8 \%\right)$ and $1.54\left(\mathrm{I}^{2} 74.3 \%\right)$, respectively; excluding the study, the RRs were $1.96\left(\mathrm{I}^{2}\right.$ $81.8 \%)$ and $1.63\left(\mathrm{I}^{2} 66.4 \%\right)$, respectively.

\section{DISCUSSION}

Our study has shown that each drug used in the treatment of CIC is superior to placebo, based on the published randomized, placebo-controlled trials. All the drugs are equally efficacious for the primary endpoints of responder analysis with $\geq 3 \mathrm{CSBM}$ /week and increase over baseline by $\geq 1 \mathrm{CSBM} /$ week, in the network meta-analysis. Bisacodyl may be superior to all the other drugs in the secondary endpoint of $\Delta_{b}$ SBM/week and in comparison with some of the drugs in $\Delta_{\mathrm{b}} \mathrm{CSBM} /$ week.

There are, however, limitations in this appraisal of relatively greater efficacy of bisacodyl. There is only one bisacodyl trial with only 4 weeks of treatment compared to other drugs which provided treatment for 12 or 24 weeks. Confirmation of superiority of any of these pharmacotherapies requires direct comparisons of the active interventions using randomized, placebo-controlled trials. A network meta-analysis has distinct features in the absence of trials of direct comparisons of treatments, and may inform judicious selection of treatment. The International Society for Pharmacoeconomics and Outcomes Research (ISPOR) recommends use of multiple treatment meta-analyses in synthesis of data, even with nodal networks, as it allows for more statistically sound assessment of comparative efficacy.[34]

Typically, patients in these randomized, placebo-controlled trials fulfilled Rome II or III criteria for constipation after exclusion of medical and structural conditions. [35] These symptom-based criteria do not differentiate groups, based on the pathophysiology causing CIC. Based on a study of symptoms and pathophysiology in 1411 patients, subgroups of CIC were 
Nelson, Camilleri, et al. - 17 -

identified, based on pathophysiology: normal transit constipation (NTC) in $\sim 70 \%$, dyssynergic defecation in $\sim 25 \%$, and slow transit constipation (STC) in $\sim 4.5 \%$. [36] In fact, epidemiological studies also have shown that about one-third of people in the community who experience constipation endorse symptoms consistent with dyssynergic defecation.[4] With a preponderance of CIC patients being female and having NTC, the similar efficacy to all the classes of drugs for the treatment of $\mathrm{CIC}$ is not surprising.

Prior randomized, placebo-controlled trials included in this analysis did not subgroup patients according to pathophysiology; hence, we are unable to report efficacy in subgroups of CIC. It is conceivable that patients with STC might respond better to treatment with agents that have significant effects on colonic motor function. Several of the agents evaluated in this network meta-analysis accelerate colonic transit, including intestinal secretagogues (lubiprostone,[37] linaclotide,[38] and the bile acid transport inhibitor, elobixibat [39]) and prokinetic agents (prucalopride,[40] tegaserod,[41] and bisacodyl [42]). However, among all these drugs, only prucalopride [43] and bisacodyl have been shown to increase the number of high amplitude propagated contractions (HAPC), which are highly propulsive in the colon.[44] Lubiprostone did not induce colonic high amplitude contractions.[45]

A recent consensus monograph, based on meta-analysis of treatments of CIC, gave strong recommendation for treatment with fiber, osmotic laxatives (PEG, lactulose), stimulant laxatives (NaP and bisacodyl), prucalopride, linaclotide and lubiprostone.[46] However, the quality of evidence was considered moderate in some of the trials, there were no direct comparisons between active drugs, and the analysis used as primary endpoint the failure to respond to therapy. This appraisal actually combined in non-responder status failure to respond to different endpoints in each trial. In addition, the secondary endpoints evaluated did not differentiate SBM from 
Nelson, Camilleri, et al. - 18 -

CSBM. Despite these methodological differences, our direct and network meta-analyses confirm the general conclusion of the prior report regarding the efficacy of each intervention relative to placebo with reference to the primary endpoints (which are the components of the endpoint currently recommended by FDA), although there is a possible difference in efficacy on secondary endpoints between bisacodyl and other drugs.

Our study has some limitations. There is only one randomized, placebo-controlled trial for 4 of the drugs included in the meta-analysis ( $\mathrm{NaP}$, bisacodyl, velusetrag and elobixibat), and osmotic laxatives such as PEG, lactulose, and magnesium salts were not included, since the endpoints in those studies were not uniform or consistent with the inclusion criteria. This particularly applies to the trials with PEG. $[47,48,49,50]$ There is one randomized, placebocontrolled trial directly comparing PEG3350 + electrolytes (PEG3350+E) to prucalopride treatment,[51] but this was a single-center study conducted in a controlled environment on patients many of whom had features suggesting evacuation disorder at baseline: $\sim 50 \%$ reported sensation of anal blockage and $15 \%$ manual maneuvers to facilitate defecation. Moreover, the primary endpoint was the proportion of patients having $\geq 3 \mathrm{SCBMs}$ during the last week of treatment in a 4-week trial, rather than the entire treatment period, and the randomized, placebocontrolled trial showed non-inferiority of PEG3350 + E to prucalopride, consistent with our general conclusion that the approved pharmacotherapies for CIC have similar efficacy.

Other limitations in our network meta-analysis are the variability in the duration of treatment (4 to 24 weeks) and safety and adverse events for the drugs were not analyzed in our study. Another limitation is that, in many of these pivotal clinical trials, bisacodyl is often used as the rescue medication, and the impact of this on the "placebo" arms could not be appraised as it is not reported in detail in the trials. It is also conceivable that the high number of prucalopride 
Nelson, Camilleri, et al. - 19 -

trials impacted the relative assessment of efficacy by reducing the width of the confidence

interval of the RR; therefore, we have interpreted cautiously the RR differences between

prucalopride and velusetrag which was the only medication identified as less efficacious than

prucalopride in the statistical analysis.

Strengths in our study design and network meta-analysis include trials with similar

patient population, comparators, outcome assessments, and trial design; application of the

GRADE approach to provide an objective and transparent assessment of the quality of evidence

for evaluating comparative efficacy of these agents;[52] and the inclusion of the responder

analyses as well as secondary endpoints which are very relevant in view of differences in

baseline SBM and CSBM between studies.[53]

In conclusion, network meta-analysis shows that current pharmacotherapies for CIC have similar efficacy. Based on secondary endpoints, bisacodyl may be superior to other medications prescribed for $\mathrm{CIC}$; however, bisacodyl is associated with abdominal cramps and diarrhea. In the future, head-to-head trials of active agents are necessary to determine the efficacy and adverse effects in order to facilitate optimal selection of pharmacological agents for CIC instead of the current choice based on failure of prior drugs. 
Acknowledgements: We thank Dr. Fabio Cataldi and Dr. Debra Silberg (Shire Pharmaceuticals, Turnhout, Belgium), the late Dr. Hans Graffner (Albireo, Göteborg, Sweden), Dr. Sabine Niedermeier (Boehringer Ingelheim Pharma GmbH \& Co. KG, Ingelheim, Germany), Dr. Peter Lichtlen (Sucampo AG, Bethesda, MD), Dr. Fukudo Shin (Tohoku University, Sendai, Japan), Dr. Michael A Kamm (University of Melbourne, Melbourne, Australia) and Dr. Stefan MuellerLissner (Lehrkrankenhaus der Charité, Universitätsmedizin, Berlin, Germany) for providing access to clinical trial data for medications reviewed in this article.

Funding: Dr. Camilleri is supported by grant R01-DK92179 from National Institutes of Health for studies on lower functional gastrointestinal disorders.

Competing Interests: Dr. Camilleri received grants for research on pharmacodynamics of prucalopride, velusetrag, elobixibat, linaclotide, and lubiprostone in the past decade. Dr. Camilleri serves as an advisor to Albireo, Rhythm, and Theravance, with compensation for his time serving as an advisor paid to his employer, Mayo Clinic, not to himself personally. $\underline{\text { The other authors have no competing interests. }}$

\section{Authors' contributions:}

Alfred D. Nelson: concept development, data analysis, selection of articles, authorship Michael Camilleri: concept development, data analysis, selection of articles, authorship Sakkarin Chirapongsathorn: network meta-analysis, authorship Priya Vijayvargiya: assessment of study quality, authorship Nelson Valentin: selection of articles to be included after the literature search, authorship Andrea Shin: analysis of data on $5 \mathrm{HT}_{4}$ agonists, authorship Patricia J. Erwin: literature search for systematic review, authorship Zhen Wang: network meta-analysis, authorship M. Hassan Murad: systematic review and network meta-analysis, authorship 
Nelson, Camilleri, et al. - 21 -

\section{References}

1 Suares NC, Ford AC. Prevalence of, and risk factors for, chronic idiopathic constipation in the community: systematic review and meta-analysis. Am J Gastroenterol 2011;106:1582-91; quiz $1,92$.

2 Longstreth GF, Thompson WG, Chey WD, et al. Functional Bowel Disorders. Gastroenterology 2006;130:1480-91.

3 Peery AF, Crockett SD, Barritt AS, et al. Burden of Gastrointestinal, Liver, and Pancreatic Diseases in the United States. Gastroenterology 2015;149:1731-41.e3.

4 Bharucha AE, Pemberton JH, Locke III GR. American Gastroenterological Association Technical Review on Constipation. Gastroenterology 2013;144:218-38.

5 Voderholzer WA, Schatke W, Muhldorfer BE, et al. Clinical response to dietary fiber treatment of chronic constipation. Am J Gastroenterol 1997;92:95-8.

6 Ford AC, Suares NC. Effect of laxatives and pharmacological therapies in chronic idiopathic constipation: systematic review and meta-analysis. Gut 2011;60:209-18.

7 http://www.ema.europa.eu/docs/en_GB/document_library/Scientific_guideline/ 2014/02/WC500162134.pdf

8 Higgins JP, Strene JAC. Cochrane Handbook for Systematic Reviews of interventions In: Higgins JP and Green S ed. Available from www.cochrane-handbook.org.: The Cochrane Collaboration; 2011.

9 Hutton B, Salanti G, Caldwell DM, et al. The PRISMA Extension Statement for Reporting of Systematic Reviews Incorporating Network Meta-analyses of Health Care Interventions: Checklist and ExplanationsPRISMA Extension for Network Meta-analysis. Annals of Internal Medicine 2015;162:777-84.

10 White IR, Barrett JK, Jackson D, et al. Consistency and inconsistency in network metaanalysis: model estimation using multivariate meta-regression. Research Synthesis Methods 2012;3:111-25.

11 Ioannidis JP, Trikalinos TA. The appropriateness of asymmetry tests for publication bias in meta-analyses: a large survey. CMAJ 2007;176:1091-6.

12 Guyatt G, Oxman AD, Sultan S, et al. GRADE guidelines: 11. Making an overall rating of confidence in effect estimates for a single outcome and for all outcomes. Journal of Clinical Epidemiology 2013;66:151-7.

13 Camilleri M, Kerstens R, Rykx A, et al. A Placebo-Controlled Trial of Prucalopride for Severe Chronic Constipation. New England Journal of Medicine 2008;358:2344-54.

14 Coremans G, Kerstens R, De Pauw M, et al. Prucalopride is effective in patients with severe chronic constipation in whom laxatives fail to provide adequate relief. Results of a double-blind, placebo-controlled clinical trial. Digestion 2003;67:82-9.

15 Ke M, Zou D, Yuan Y, et al. Prucalopride in the treatment of chronic constipation in patients from the Asia-Pacific region: a randomized, double-blind, placebo-controlled study. Neurogastroenterology \& Motility 2012;24:999-e541.

16 Müller-lissner S, Rykx A, Kerstens R, et al. A double-blind, placebo-controlled study of prucalopride in elderly patients with chronic constipation. Neurogastroenterology \& Motility 2010;22:991-e255.

17 Piessevaux H, Corazziari E, Rey E, et al. A randomized, double-blind, placebo-controlled trial to evaluate the efficacy, safety, and tolerability of long-term treatment with prucalopride. Neurogastroenterology \& Motility 2015;27:805-15. 
18 Quigley EMM, Vandeplassche L, Kerstens R, et al. Clinical trial: the efficacy, impact on quality of life, and safety and tolerability of prucalopride in severe chronic constipation - a 12week, randomized, double-blind, placebo-controlled study. Alimentary Pharmacology \& Therapeutics 2009;29:315-28.

19 Tack J, van Outryve M, Beyens G, et al. Prucalopride (Resolor) in the treatment of severe chronic constipation in patients dissatisfied with laxatives. Gut 2009;58:357-65.

20 Emmanuel AV, Roy AJ, Nicholls TJ, et al. Prucalopride, a systemic enterokinetic, for the treatment of constipation. Alimentary Pharmacology \& Therapeutics 2002;16:1347-56.

21 Yiannakou Y, Piessevaux H, Bouchoucha M, et al. A Randomized, Double-Blind, Placebo-Controlled, Phase 3 Trial to Evaluate the Efficacy, Safety, and Tolerability of Prucalopride in Men With Chronic Constipation. Am J Gastroenterol 2015;110:741-8. 22 Johanson JF, Morton D, Geenen J, et al. Multicenter, 4-Week, Double-Blind, Randomized, Placebo-Controlled Trial of Lubiprostone, a Locally-Acting Type-2 Chloride Channel Activator, in Patients With Chronic Constipation. Am J Gastroenterol 2008;103:170-7. 23 Barish CF, Drossman D, Johanson JF, et al. Efficacy and safety of lubiprostone in patients with chronic constipation. Dig Dis Sci 2010;55:1090-7.

24 Fukudo S, Hongo M, Kaneko H, et al. Lubiprostone Increases Spontaneous Bowel Movement Frequency and Quality of Life in Patients With Chronic Idiopathic Constipation. Clinical Gastroenterology and Hepatology 2015;13:294-301.e5.

25 Lacy BE, Schey R, Shiff SJ, et al. Linaclotide in Chronic Idiopathic Constipation Patients with Moderate to Severe Abdominal Bloating: A Randomized, Controlled Trial. PLoS ONE 2015;10:e0134349.

26 Lembo AJ, Kurtz CB, MacDougall JE, et al. Efficacy of Linaclotide for Patients With Chronic Constipation. Gastroenterology 2010;138:886-95.e1.

27 Lembo AJ, Schneier HA, Shiff SJ, et al. Two Randomized Trials of Linaclotide for Chronic Constipation. New England Journal of Medicine 2011;365:527-36.

28 Fried M, Johanson JF, Gwee KA, et al. Efficacy of Tegaserod in Chronic Constipation in Men. Am J Gastroenterol 2007;102:362-70.

29 Kamm MA, Muller-Lissner S, Talley NJ, et al. Tegaserod for the Treatment of Chronic Constipation: A Randomized, Double-Blind, Placebo-Controlled Multinational Study. Am J Gastroenterol 2005;100:362-72.

30 Goldberg M, Li YP, Johanson JF, et al. Clinical trial: the efficacy and tolerability of velusetrag, a selective 5-HT4 agonist with high intrinsic activity, in chronic idiopathic constipation - a 4-week, randomized, double-blind, placebo-controlled, dose-response study. Alimentary Pharmacology \& Therapeutics 2010;32:1102-12.

31 Chey WD, Camilleri M, Chang L, et al. A Randomized Placebo-Controlled Phase IIb Trial of A3309, A Bile Acid Transporter Inhibitor, for Chronic Idiopathic Constipation. Am J Gastroenterol 2011;106:1803-12.

32 Kamm MA, Mueller-Lissner S, Wald A, et al. Oral Bisacodyl Is Effective and WellTolerated in Patients With Chronic Constipation. Clinical Gastroenterology and Hepatology 2011;9:577-83.

33 Mueller-Lissner S, Kamm MA, Wald A, et al. Multicenter, 4-Week, Double-Blind, Randomized, Placebo-Controlled Trial of Sodium Picosulfate in Patients With Chronic Constipation. Am J Gastroenterol 2010;105:897-903. 
34 Hoaglin DC, Hawkins N, Jansen JP, et al. Conducting indirect-treatment-comparison and network-meta-analysis studies: report of the ISPOR Task Force on Indirect Treatment Comparisons Good Research Practices: part 2. Value Health 2011;14:429-37.

35 Locke III GR, Pemberton JH, Phillips SF. AGA technical review on constipation. Gastroenterology 2000;119:1766-78.

36 Nullens S, Nelsen T, Camilleri M, et al. Regional colon transit in patients with dyssynergic defaecation or slow transit in patients with constipation. Gut 2012;61:1132-9.

37 Camilleri M, Bharucha AE, Ueno R, et al. Effect of a selective chloride channel activator, lubiprostone, on gastrointestinal transit, gastric sensory, and motor functions in healthy volunteers. American Journal of Physiology - Gastrointestinal and Liver Physiology 2006;290:G942-G7.

38 Andresen V, Camilleri M, Busciglio IA, et al. Effect of 5 Days Linaclotide on Transit and Bowel Function in Females With Constipation-Predominant Irritable Bowel Syndrome. Gastroenterology 2007;133:761-8.

39 Wong BS, Camilleri M, McKinzie S, et al. Effects of A3309, an Ileal Bile Acid Transporter Inhibitor, on Colonic Transit and Symptoms in Females With Functional Constipation. Am J Gastroenterol 2011;106:2154-64.

40 Bouras EP, Camilleri M, Burton DD, et al. Prucalopride accelerates gastrointestinal and colonic transit in patients with constipation without a rectal evacuation disorder.

Gastroenterology 2001;120:354-60.

41 Prather CM, Camilleri M, Zinsmeister AR, et al. Tegaserod accelerates orocecal transit in patients with constipation-predominant irritable bowel syndrome. Gastroenterology 2000;118:463-8.

42 Manabe N, Cremonini F, Camilleri M, et al. Effects of bisacodyl on ascending colon emptying and overall colonic transit in healthy volunteers. Alimentary Pharmacology \& Therapeutics 2009;30:930-6.

43 Miner P, Camilleri M, Burton D, et al. Prucalopride induces high amplitude propagated contractions in the colon of patients with chronic constipation: A randomized study. Neurogastroenterology and Motility 2015;27:86-.

44 Preston DM, Lennard-Jones JE. Pelvic motility and response to intraluminal bisacodyl in slow-transit constipation. Dig Dis Sci 1985;30:289-94.

45 Sweetser S, Busciglio IA, Camilleri M, et al. Effect of a chloride channel activator, lubiprostone, on colonic sensory and motor functions in healthy subjects. American Journal of Physiology - Gastrointestinal and Liver Physiology 2009;296:G295-G301.

46 Ford AC, Moayyedi P, Lacy BE, et al. American College of Gastroenterology Monograph on the Management of Irritable Bowel Syndrome and Chronic Idiopathic Constipation. Am J Gastroenterol 2014;109:S2-S26.

47 DiPalma JA, Cleveland MB, McGowan J, et al. A comparison of polyethylene glycol laxative and placebo for relief of constipation from constipating medications. South Med J 2007;100:1085-90.

48 DiPalma JA, Cleveland Mv, McGowan J, et al. A Randomized, Multicenter, PlaceboControlled Trial of Polyethylene Glycol Laxative for Chronic Treatment of Chronic Constipation. Am J Gastroenterol 2007;102:1436-41.

49 Corazziari E, Badiali D, Bazzocchi G, et al. Long term efficacy, safety, and tolerabilitity of low daily doses of isosmotic polyethylene glycol electrolyte balanced solution (PMF-100) in the treatment of functional chronic constipation. Gut 2000;46:522-6. 
50 Corazziari E, Badiali D, Habib FI, et al.. Small volume isosmotic polyethylene glycol electrolyte balanced solution (PMF-100) in treatment of chronic nonorganic constipation. Dig Dis Sci 1996;41:1636-42.

51 Cinca R, Chera D, Gruss HJ, et al. Randomised clinical trial: macrogol/PEG $3350+$ electrolytes versus prucalopride in the treatment of chronic constipation - a comparison in a controlled environment. Alimentary Pharmacology \& Therapeutics 2013;37:876-86.

52 Puhan MA, Schünemann HJ, Murad MH, et al. A GRADE Working Group approach for rating the quality of treatment effect estimates from network meta-analysis. BMJ 2014;349. 53 Bielefeldt K, Levinthal DJ, Nusrat S. Effective Constipation Treatment Changes More Than Bowel Frequency: A Systematic Review and Meta-Analysis. Journal of Neurogastroenterology and Motility 2016;22:31-45. 
Table 1. Study Characteristics

\begin{tabular}{|c|c|c|c|c|c|c|c|c|c|}
\hline Study ID & Location & Drug & $\begin{array}{l}\text { Doses } \\
\text { tested }\end{array}$ & $\begin{array}{l}\text { Study } \\
\text { Duration } \\
\text { (weeks) }\end{array}$ & $\begin{array}{l}\text { Number Total: } \\
\text { Intervention/ } \\
\text { control }\end{array}$ & Age (I) & Age (C) & $\begin{array}{l}\text { Gender, } \\
\text { F \% }\end{array}$ & Constipation criteria \\
\hline $\begin{array}{l}\text { Camilleri } \\
2008\end{array}$ & USA & PRU & $\begin{array}{l}2 \mathrm{mg} \\
4 \mathrm{mg} \mathrm{QD}\end{array}$ & 12 & 620: $411 / 209$ & $48.0 \pm 14.3$ & $48.9 \pm 13.0$ & 87.1 & $\begin{array}{l}\leq 2 \mathrm{CSBM} \text { /week for } 6 \text { months, and } \\
\text { Rome III criteria\# }\end{array}$ \\
\hline $\begin{array}{l}\text { Coremans } \\
2003\end{array}$ & Belgium & PRU & $4 \mathrm{mg}$ QD & 4 & 53: $27 / 26$ & $43.8 \pm 2.7$ & $47.4 \pm 2.9$ & 98.1 & $\begin{array}{l}\geq 2 \text { of the following for } 6 \text { months: } 2 \\
\text { SBM/week and Rome III criteria }{ }^{\#}\end{array}$ \\
\hline Ke 2012 & $\begin{array}{l}\text { Asia- } \\
\text { pacific }\end{array}$ & PRU & $2 \mathrm{mg}$ QD & 12 & 501: $249 / 252$ & $\begin{array}{c}41.4 \pm 12.9 \\
2\end{array}$ & $41.8 \pm 12.9$ & 90 & $\begin{array}{l}\leq 2 \mathrm{SBM} / \text { week on average, and } \geq 1 \text { of } \\
\text { the following in Rome III criteria* }\end{array}$ \\
\hline $\begin{array}{l}\text { Mueller- } \\
\text { Lissner } 2010\end{array}$ & Int & PRU & $\begin{array}{l}1 \mathrm{mg} \\
2 \mathrm{mg} \\
4 \mathrm{mg} \text { QD }\end{array}$ & 4 & 300: $230 / 70$ & $76.5 \pm 7.7$ & $76 \pm 7.4$ & 70.3 & $\begin{array}{l}\leq 2 \mathrm{CSBM} / \text { week for } 6 \text { months and } \geq 1 \text { of } \\
\text { the following in Rome III criteria }{ }^{\#}\end{array}$ \\
\hline $\begin{array}{l}\text { Piessevaux } \\
2015\end{array}$ & Europe & PRU & $2 \mathrm{mg} \mathrm{QD}$ & 24 & 346: $177 / 169$ & $49.4 \pm 15.8$ & $48.3 \pm 16.3$ & $14.7^{\$}$ & $\begin{array}{l}\leq 2 \mathrm{CSBM} / \text { week and } \geq 1 \text { of the } \\
\text { following in Rome III criteria\# for } 6 \\
\text { months }\end{array}$ \\
\hline $\begin{array}{l}\text { Quigley } \\
2009\end{array}$ & USA & PRU & $\begin{array}{l}2 \mathrm{mg} \\
4 \mathrm{mg} Q \mathrm{QD}\end{array}$ & 12 & 641: 429/212 & $48.9 \pm 13.9$ & $46.2 \pm 13.0$ & 86.6 & $\begin{array}{l}\leq 2 \mathrm{CSBM} / \text { week for } 6 \text { months and } \geq 1 \text { of } \\
\text { the following in Rome III criteria }{ }^{\#} \text { for } 6 \\
\text { months }\end{array}$ \\
\hline Tack 2009 & Int & PRU & $\begin{array}{l}2 \mathrm{mg} \\
4 \mathrm{mg} \mathrm{QD}\end{array}$ & 12 & 713: $473 / 240$ & $44.1 \pm 15.1$ & $43.7 \pm 15.3$ & 90.8 & $\begin{array}{l}\leq 2 \mathrm{CSBM} / \text { week for } 6 \text { months and } \geq 1 \text { of } \\
\text { the following in Rome III criteria\# for } \\
6 \text { months }\end{array}$ \\
\hline $\begin{array}{l}\text { Emmanuel } \\
2002\end{array}$ & UK & PRU & $1 \mathrm{mg}$ QD & 4 & $74: 37 / 37$ & NA & NA & 100 & $\begin{array}{l}\leq 2 \mathrm{SBM} / \text { week and need to strain at } \\
\text { least } 25 \% \text { of the defecation. }\end{array}$ \\
\hline $\begin{array}{l}\text { Yiannnakou } \\
2015\end{array}$ & Europe & PRU & $2 \mathrm{mg}$ QD & 12 & 370: $184 / 186$ & $58.4 \pm 17.6$ & $58.5 \pm 16.3$ & $0^{\mathbb{T}}$ & $\begin{array}{l}\leq 2 \mathrm{CSBM} / \text { week for } 6 \text { months and } \geq 1 \text { of } \\
\text { the following in Rome III criteria” for } \\
6 \text { months }\end{array}$ \\
\hline $\begin{array}{l}\text { Goldberg } \\
2010\end{array}$ & USA & VEL & $\begin{array}{l}15 \mathrm{mg} \\
30 \mathrm{mg} \\
45 \mathrm{mg} \\
\text { QD }\end{array}$ & 4 & 401: $294 / 107$ & $44.4 \pm 11.7$ & $45.4 \pm 10.0$ & 92.0 & $\begin{array}{l}\geq 18 \text { years of age satisfying Rome } 3 \\
\text { criteria functional constipation* }\end{array}$ \\
\hline Fried 2007 & Int & TEG & $6 \mathrm{mg}$ bid & 12 & 322: $158 / 164$ & $51.1 \pm 17.1$ & $51.8 \pm 17.2$ & $0^{\text {qI }}$ & $\begin{array}{l}\leq 3 \mathrm{CSBM} / \text { week and } \geq 1 \text { of the } \\
\text { following in Rome III criteria }{ }^{\#} \text { for } 6 \\
\text { months }\end{array}$ \\
\hline Kamm 2005 & Int & TEG & $\begin{array}{l}2 \mathrm{mg} \\
6 \mathrm{mg} \text { bid }\end{array}$ & 12 & 1264: 848/416 & $46.3 \pm 15.2$ & $46.0 \pm 15.6$ & 86.3 & $\begin{array}{l}\leq 3 \mathrm{CSBM} / \text { week and } \geq 1 \text { of the } \\
\text { following in Rome III criteria" for } 6 \\
\text { months }\end{array}$ \\
\hline
\end{tabular}




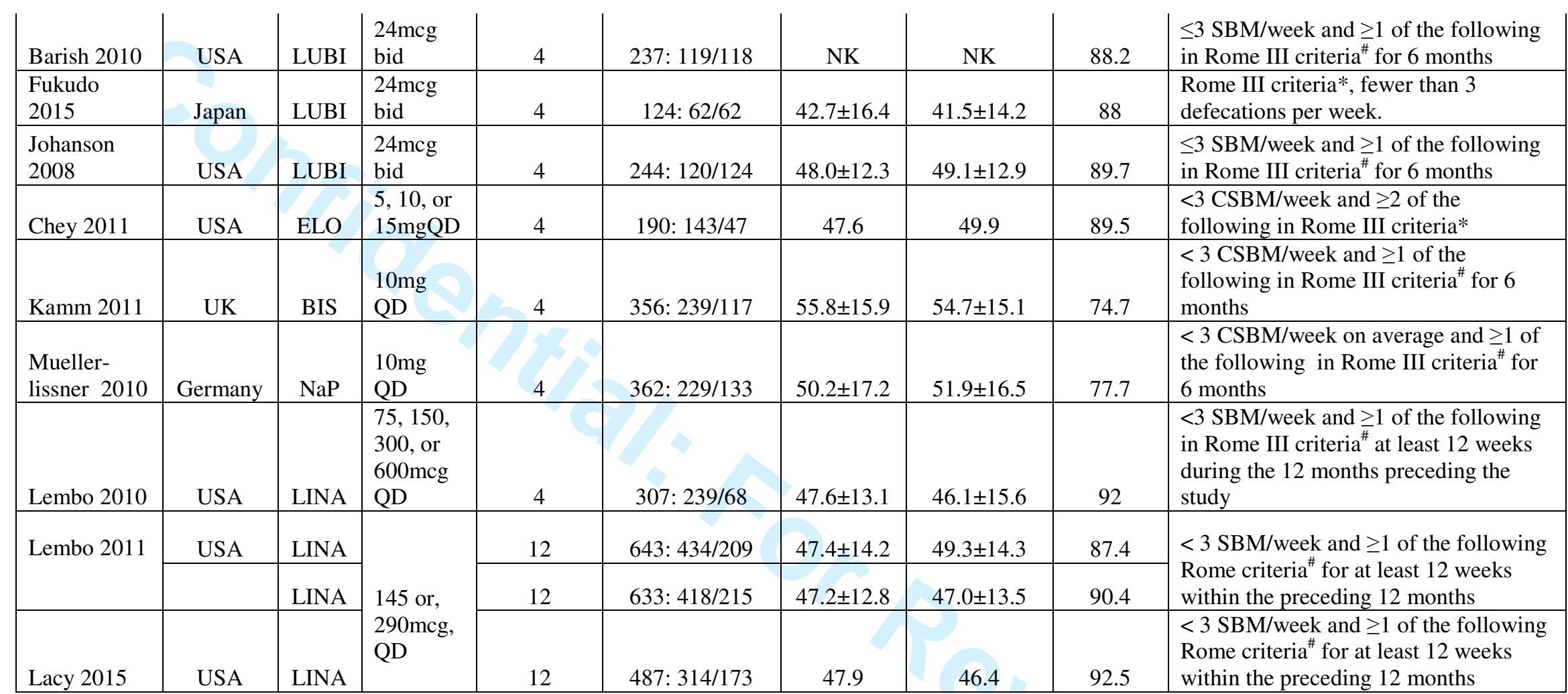

*- Rome III criteria which includes straining,

\# - Part of the Rome III criteria which includes $\geq 25 \%$ straining, incomplete evacuation and hard/lumpy stools,

$\$-85.32 \%$ were male, ${ }^{\text {II }} 100 \%$ were men,

PRU- Prucalopride, VEL- Velusetrag, TEG- Tegaserod, LUBI- Lubiprostone, ELO- Elobixibat, BIS- Bisacodyl, NaP- Sodium Picosulphate, LINA- Linaclotide, MC- Multicenter, SC- Single center, Int- International, I- Intervention, C- Control. 
Table 2. Study Quality (CGR=computer generated randomization; Rx=intervention arm, $\mathrm{C}=$ control; $\mathrm{LOCF}=$ last observation carried forward; PRU=prucalopride, VEL=velusetrag, TEG=tegaserod, LUBI=lubiprostone, $\mathrm{ELO}=$ =lobixibat, $\mathrm{BIS}=\mathrm{bisacodyl}$, NaP=sodium picosulphate, LINA=linaclotide)

\begin{tabular}{|c|c|c|c|c|c|c|c|}
\hline Study Identification & Drug & Generation of randomization sequence & $\begin{array}{l}\text { Allocation } \\
\text { concealment }\end{array}$ & $\begin{array}{l}\text { Double } \\
\text { Blind }\end{array}$ & $\begin{array}{l}\text { Lost to } \\
\text { follow up }\end{array}$ & $\begin{array}{l}\text { Methods used } \\
\text { for missing data }\end{array}$ & $\begin{array}{l}\text { Overall } \\
\text { Quality }\end{array}$ \\
\hline Camilleri 2008 & PRU & Consecutive numbering + block randomization of 3 & + & + & $5 \mathrm{Rx}, 3 \mathrm{C}$ & Imputation & High \\
\hline Coremans 2003 & PRU & Unclear & Unclear & + & 0 & - & Mod \\
\hline Ke 2012 & PRU & CGR & + & + & $3 \mathrm{Rx}, 2 \mathrm{C}$ & NS & Mod \\
\hline Mueller-Lissner 2010 & PRU & Randomization code generated by sponsor & + & + & 0 & $\begin{array}{l}\text { Considered as } \\
\text { non-responders }\end{array}$ & High \\
\hline Piessevaux 2015 & PRU & Randomization by web-based/voice-response system. & + & + & 0 & Imputation & Low \\
\hline Quigley 2009 & PRU & Block randomization of three & + & + & $5 \mathrm{Rx}, 2 \mathrm{C}$ & Imputation & High \\
\hline Tack 2009 & PRU & Random allocation sequence by the investigator & Unclear & + & $5 \mathrm{Rx}, 1 \mathrm{C}$ & $\begin{array}{l}\text { Considered as } \\
\text { non-responders }\end{array}$ & High \\
\hline Emmanuel 2002 & PRU & Method not known & Unclear & + & ORx, $1 \mathrm{C}$ & NS & Mod \\
\hline Yiannnakou 2015 & PRU & Central interactive web based response system & + & + & $2 \mathrm{Rx}, \mathrm{OC}$ & Imputation & Mod \\
\hline Goldberg 2010 & VEL & $\begin{array}{l}\text { Telephonic interactive voice response system using a } \\
\text { permuted block algorithm }\end{array}$ & + & + & NK & LOCF & High \\
\hline Fried 2007 & TEG & $\begin{array}{l}\text { Validated system that automated the random } \\
\text { assignment by sponsor }\end{array}$ & + & + & 0 & - & High \\
\hline Kamm 2005 & TEG & Randomized using validated computer system & + & + & $26 \mathrm{Rx}, 10 \mathrm{C}$ & NS & Mod \\
\hline Barish 2010 & LUBI & Block randomization of four & + & + & $4 \mathrm{Rx}, 1 \mathrm{C}$ & LOCF & Mod \\
\hline Fukudo 2015 & LUBI & Method not known & Unclear & + & 0 & - & Mod \\
\hline Johanson 2008 & LUBI & Block randomization of four & + & + & $1 \mathrm{Rx}, 2 \mathrm{C}$ & LOCF & Mod \\
\hline Chey 2011 & ELO & CGR by sponsor & + & + & $1 \mathrm{Rx}, 0 \mathrm{C}$ & NS & Mod \\
\hline Kamm 2011 & BIS & CGR & + & + & 0 & - & High \\
\hline Mueller-Lissner 2010 & $\mathrm{NaP}$ & CGR & + & + & 0 & & High \\
\hline Lembo 2010 & LINA & CGR using a block size of 5 & + & + & $3 \mathrm{Rx}, 0 \mathrm{C}$ & \multirow{2}{*}{$\begin{array}{l}\text { Observed-cases } \\
\text { approach }\end{array}$} & Mod \\
\hline Lembo 2011 & LINA & CGR using a block size of 6 & + & + & $29 \mathrm{Rx}, 4 \mathrm{C}$ & & High \\
\hline Lacy 2015 & LINA & $\begin{array}{l}\text { Randomization by statistical programmer not } \\
\text { involved in the trial }\end{array}$ & + & + & $10 \mathrm{Rx}, 5 \mathrm{C}$ & $\begin{array}{l}\text { Considered as } \\
\text { non-responders }\end{array}$ & High \\
\hline
\end{tabular}


Table 3. Pooled RR, and 95\% confidence intervals (for network meta-analysis) for primary endpoints (p<0.05 is bolded). (Note: For lubiprostone, both of the endpoints are not available +=Superior, -=Inferior).

\section{A. Responders with $\geq 3$ CSBM per week for the drugs for CIC}

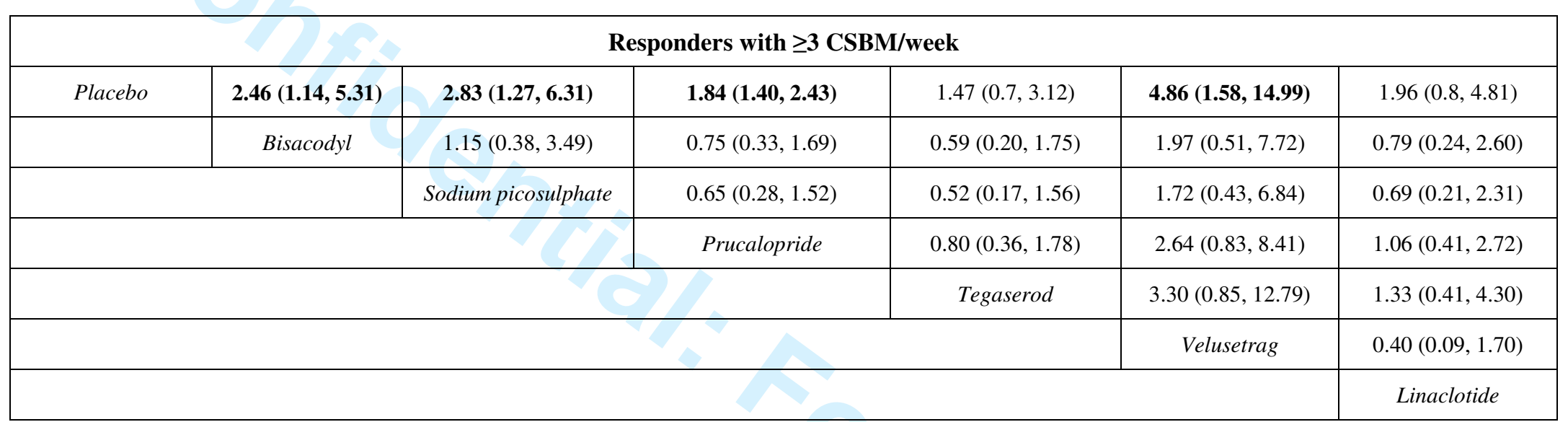

3B. Responders with $\geq 1$ CSBM per week for the drugs for CIC

\begin{tabular}{|c|c|c|c|c|c|c|c|}
\hline \multicolumn{8}{|c|}{ Responders with increase over baseline by $\geq \mathbf{1}$ CSBM/week } \\
\hline \multirow[t]{8}{*}{ Placebo } & $2.04(1.3,3.19)$ & $2.03(1.27,3.23)$ & $1.54(1.30,1.83)$ & $1.33(0.97,1.83)$ & $3.1(1.61,5.95)$ & $1.72(1.0,2.96)$ & $1.97(1.09,3.55)$ \\
\hline & Bisacodyl & $0.99(0.52,1.9)$ & $0.76(0.47,1.22)$ & $0.65(0.38,1.13)$ & $1.52(0.69,3.35)$ & $0.84(0.42,1.71)$ & $0.96(0.46,2.02)$ \\
\hline & & Sodium picosulphate & $0.76(0.46,1.25)$ & $0.66(0.37,1.16)$ & $1.53(0.69,3.41)$ & $0.85(0.42,1.74)$ & $0.97(0.46,2.06)$ \\
\hline & & & Prucalopride & $0.86(0.60,1.23)$ & $2.01(1.02,3.93)$ & $1.11(0.63,1.97)$ & $1.27(0.69,2.35)$ \\
\hline & & & & Tegaserod & $2.33(1.13,4.80)$ & $1.29(0.69,2.42)$ & $1.48(0.76,2.89)$ \\
\hline & & & & & Velusetrag & $0.56(0.24,1.30)$ & $0.64(0.26,1.53)$ \\
\hline & & & & & & Linaclotide & $1.14(0.51,2.55)$ \\
\hline & & & & & & & Elobixibat \\
\hline
\end{tabular}


Table 4. Pooled weighted mean difference, and $95 \%$ confidence intervals (for network meta-analysis) for Secondary endpoints ( $p<0.05$ is bolded). (Note: Tegaserod both of the endpoints are not available, $+=$ Superior, $-=$ Inferior).

4A. Number of CSBM change from baseline for the drugs for CIC

\begin{tabular}{|c|c|c|c|c|c|}
\hline \multicolumn{6}{|c|}{ \# of CSBM/week change from baseline } \\
\hline \multirow[t]{2}{*}{ Placebo } & $3.2(2.37,4.03)$ & $2.0(1.19,2.81)$ & $0.9(0.52,1.28)$ & $1.55(0.90,2.19)$ & $1.99(0.77,3.22)$ \\
\hline & Bisacodyl & $-1.2(-2.36,-0.04)$ & $-2.3(-3.22,-1.38)$ & $-1.65(-2.70,-0.60)$ & $-1.21(-2.69,-0.28)$ \\
\hline & & Sodium picosulphate & $-1.10(-1.99,-0.21)$ & $-0.45(-1.48,0.58)$ & $-0.01(-1.47,1.46)$ \\
\hline & & & Prucalopride & $0.65(-0.10,1.40)$ & $1.09(-0.19,2.38)$ \\
\hline & & & & Linaclotide & $0.44(-0.94,1.83)$ \\
\hline & & & & & Elobixibat \\
\hline
\end{tabular}

4B. Number of SBM change from baseline for the drugs for CIC

\begin{tabular}{|c|c|c|c|c|c|c|c|}
\hline \multicolumn{8}{|c|}{ \# of SBM/week change from baseline } \\
\hline \multirow[t]{8}{*}{ Placebo } & $4.9(3.90,5.90)$ & $3.20(2.28,4.12)$ & $1.93(1.45,2.40)$ & $2.07(1.12,3.01)$ & $2.13(1.54,2.71)$ & $2.08(0.76,3.41)$ & $1.93(1.30-2.55)$ \\
\hline & Bisacodyl & $-1.7(-3.05,-0.35)$ & $-2.97(-4.07,-1.87)$ & $-2.83(-4.20,-1.46)$ & $-2.77(-3.93,-1.62)$ & $-2.82(-4.48,-1.16)$ & $-2.97(-4.14--1.79)$ \\
\hline & & Sodium picosulphate & $-1.27(-2.30,-0.24)$ & $-1.13(-2.45,0.18)$ & $-1.07(-2.16,0.01)$ & $-1.12(-2.73,0.49)$ & $-1.27(-2.38--0.16)$ \\
\hline & & & Prucalopride & $0.14(-0.92,1.20)$ & $0.2(-0.55,0.95)$ & $0.15(-1.26,1.56)$ & $0(-0.79-0.79)$ \\
\hline & & & & Velusetrag & $0.06(-1.05,1.17)$ & $0.01(-1.61,1.64)$ & $-0.14(-1.27-0.99)$ \\
\hline & & & & & Linaclotide & $-0.04(-1.49,1.40)$ & $-0.2(-1.05-0.66)$ \\
\hline & & & & & & Elobixibat & $-0.15(-1.62-1.31)$ \\
\hline & & & & & & & Lubiprostone \\
\hline
\end{tabular}




\section{Table 5. Quality of Evidence for Responders with $\geq 1$ CSBM}

(\# -Inconsistency, \#\# -Severe inconsistency, \$ -Indirectness, \$ -Severe indirectness, * - Imprecision, **- Severe imprecision, ${ }^{\S}$-Risk of bias, p<0.05 is bolded)

\begin{tabular}{|c|c|c|c|c|c|c|}
\hline Comparison & Direct & Quality of evidence & Indirect & Quality of evidence & Network & Quality of evidence \\
\hline Bisacodyl v Placebo & $2.04(1.62,2.57)$ & High & - & - & $2.04(1.3,3.19)$ & High \\
\hline $\mathrm{Na} P$ v Placebo & $2.03(1.56,2.64)$ & High & - & - & $2.03(1.27,3.23)$ & High \\
\hline Prucalopride v Placebo & $1.54(1.28,1.86)$ & Moderate $^{\S}$ & - & - & $1.54(1.30,1.83)$ & Moderate $^{\S}$ \\
\hline Tegaserod v Placebo & $1.32(1.14,1.52)$ & High & - & - & $1.33(0.97,1.83)$ & High \\
\hline Velusetrag v Placebo & $3.1(1.83,5.24)$ & High & - & - & $3.1(1.61,5.95)$ & High \\
\hline Linaclotide v Placebo & $1.72(1.18,2.52)$ & High & - & - & $1.72(1.0,2.96)$ & High \\
\hline Elobixibat v Placebo & $1.97(1.26,3.07)$ & Moderate $^{\S}$ & - & - & $1.97(1.09,3.55)$ & Moderate $^{\S}$ \\
\hline Na P v Bisacodyl & - & - & $0.99(0.52,1.9)$ & High & $0.99(0.52,1.9)$ & Low** \\
\hline Prucalopride v Bisacodyl & - & - & $0.76(0.47,1.22)$ & Moderate & $0.76(0.47,1.22)$ & Very Low** \\
\hline Tegaserod v Bisacodyl & - & - & $0.65(0.38,1.13)$ & High & $0.65(0.38,1.13)$ & Low** \\
\hline Velusetrag v Bisacodyl & - & - & $1.52(0.69,3.35)$ & High & $1.52(0.69,3.35)$ & Low** \\
\hline Linaclotide v Bisacodyl & - & - & $0.84(0.42,1.71)$ & High & $0.84(0.42,1.71)$ & Low** \\
\hline Elobixibat v Bisacodyl & - & - & $0.96(0.46,2.02)$ & Moderate & $0.96(0.46,2.02)$ & Very Low** \\
\hline Prucalopride v Na P & - & - & $0.76(0.46,1.25)$ & Moderate & $0.76(0.46,1.25)$ & Very Low** \\
\hline Tegaserod v Na P & - & - & $0.66(0.37,1.16)$ & High & $0.66(0.37,1.16)$ & Low** \\
\hline Velusetrag v Na P & - & - & $1.53(0.69,3.41)$ & High & $1.53(0.69,3.41)$ & Low** \\
\hline Linaclotide v $\mathrm{Na} P$ & - & - & $0.85(0.42,1.74)$ & High & $0.85(0.42,1.74)$ & Low** \\
\hline Elobixibat v Na P & - & - & $0.97(0.46,2.06)$ & Moderate & $0.97(0.46,2.06)$ & Very Low** \\
\hline Tegaserod v Prucalopride & - & - & $0.86(0.60,1.23)$ & Moderate & $0.86(0.60,1.23)$ & Very Low** \\
\hline Velusetrag v Prucalopride & - & - & $2.01(1.02,3.93)$ & Moderate & $2.01(1.02,3.93)$ & Low* \\
\hline Linaclotide v Prucalopride & - & - & $1.11(0.63,1.97)$ & Moderate & $1.11(0.63,1.97)$ & Very Low** \\
\hline Elobixibat v Prucalopride & - & - & $1.27(0.69,2.35)$ & Moderate & $1.27(0.69,2.35)$ & Very Low** \\
\hline Velusetrag v Tegaserod & - & - & $2.33(1.13,4.80)$ & High & $2.33(1.13,4.80)$ & Moderate* \\
\hline Linaclotide $\mathrm{v}$ Tegaserod & - & - & $1.29(0.69,2.42)$ & High & $1.29(0.69,2.42)$ & Low** \\
\hline Elobixibat v Tegaserod & - & - & $1.48(0.76,2.89)$ & Moderate & $1.48(0.76,2.89)$ & Very Low** \\
\hline Linaclotide v Velusetrag & - & - & $0.56(0.24,1.30)$ & High & $0.56(0.24,1.30)$ & Low** \\
\hline Elobixibat v Velusetrag & - & - & $0.64(0.26,1.53)$ & Moderate & $0.64(0.26,1.53)$ & Very Low** \\
\hline Elobixibat v Linaclotide & - & - & $1.14(0.51,2.55)$ & Moderate & $1.14(0.51,2.55)$ & Very Low** \\
\hline
\end{tabular}


Table 6. Sensitivity analysis based on dose of medication (for primary endpoints NS if RR's 95\% CI overlaps 1, for secondary endpoints NS if RR's 95\% CI overlaps 0)

\begin{tabular}{|c|c|c|c|c|c|c|c|c|c|c|c|c|}
\hline \multirow[t]{2}{*}{ Drug } & \multicolumn{3}{|c|}{ Responders with $\geq 3$ CSBM } & \multicolumn{3}{|c|}{$\begin{array}{c}\text { Responders with increase over } \\
\text { baseline by } \geq \mathbf{1 ~ C S B M}\end{array}$} & \multicolumn{3}{|c|}{$\Delta \mathrm{b}$ CSBM/wk } & \multicolumn{3}{|c|}{$\Delta \mathrm{b} \mathrm{SBM} / \mathrm{wk}$} \\
\hline & Standard & Low & High & Standard & Low & High & Standard & Low & High & Standard & Low & High \\
\hline $\begin{array}{l}\text { Bisacodyl v } \\
\text { Placebo }\end{array}$ & $\begin{array}{c}2.46 \\
(1.81 \\
3.35) \\
\end{array}$ & & - & $\begin{array}{c}2.04 \\
(1.62,2.57)\end{array}$ & - & - & $\begin{array}{c}3.2 \\
(2.66, \\
3.74) \\
\end{array}$ & - & - & $\begin{array}{c}4.90 \\
(4.14 \\
5.66) \\
\end{array}$ & - & - \\
\hline Na P v Placebo & $\begin{array}{r}2.83 \\
(1.93, \\
4.16) \\
\end{array}$ & - & - & $\begin{array}{c}2.03 \\
(1.56,2.64)\end{array}$ & - & - & $\begin{array}{c}2.0 \\
(1.51, \\
2.49) \\
\end{array}$ & - & - & $\begin{array}{c}3.20 \\
(2.55, \\
3.85) \\
\end{array}$ & - & - \\
\hline $\begin{array}{l}\text { Prucalopride v } \\
\text { Placebo }\end{array}$ & $\begin{array}{c}2.04 \\
(1.59 \\
2.62)\end{array}$ & $\begin{array}{c}1.31 \\
(0.56 \\
3.04)\end{array}$ & $\begin{array}{c}2.23 \\
(1.74, \\
2.85)\end{array}$ & $\begin{array}{c}1.54 \\
(1.24,1.92)\end{array}$ & $\begin{array}{l}1.81 \\
(1.23 \\
2.66)\end{array}$ & $\begin{array}{l}1.71 \\
(1.45, \\
2.01)\end{array}$ & $\begin{array}{c}0.88 \\
(0.49 \\
1.28)\end{array}$ & $\begin{array}{c}1.30 \\
(0.76, \\
1.84)\end{array}$ & $\begin{array}{c}0.9 \\
(0.42, \\
1.38)\end{array}$ & $\begin{array}{l}1.58 \\
(0.72 \\
2.44)\end{array}$ & $\begin{array}{c}1.85 \\
(0.79 \\
2.91)\end{array}$ & $\begin{array}{r}1.63 \\
(0.46, \\
2.81)\end{array}$ \\
\hline $\begin{array}{l}\text { Tegaserod v } \\
\text { Placebo }\end{array}$ & $\begin{array}{l}1.75 \\
(1.32 \\
2.33)\end{array}$ & $\begin{array}{l}1.18 \\
(0.86, \\
1.62)\end{array}$ & - & $\begin{array}{c}1.41 \\
(1.18,1.69)\end{array}$ & $\begin{array}{l}1.17 \\
(0.96, \\
1.42)\end{array}$ & - & - & - & - & - & - & - \\
\hline $\begin{array}{l}\text { Velusetrag v } \\
\text { Placebo }\end{array}$ & $\begin{array}{c}4.09 \\
(1.59 \\
10.51)\end{array}$ & $\begin{array}{c}5.57 \\
(2.24, \\
13.86)\end{array}$ & $\begin{array}{c}4.9 \\
(1.93, \\
12.43)\end{array}$ & $\begin{array}{c}2.49 \\
(1.38,4.46)\end{array}$ & $\begin{array}{c}3.33 \\
(1.91 \\
5.80)\end{array}$ & $\begin{array}{c}3.5 \\
(2.01 \\
6.10)\end{array}$ & & & - & $\begin{array}{l}1.90 \\
(1.23, \\
2.57)\end{array}$ & $\begin{array}{c}2.20 \\
(1.55 \\
2.85)\end{array}$ & $\begin{array}{l}2.10 \\
(1.35 \\
2.85)\end{array}$ \\
\hline $\begin{array}{l}\text { Linaclotide v } \\
\text { Placebo }\end{array}$ & $\begin{array}{r}1.92 \\
(1.03, \\
3.57)\end{array}$ & - & $\begin{array}{c}2.0 \\
(1.08, \\
\text { 3.69) }\end{array}$ & $\begin{array}{c}1.64 \\
(1.07,2.51)\end{array}$ & - & $\begin{array}{l}1.81 \\
(1.19 \\
2.73)\end{array}$ & $\begin{array}{l}1.45 \\
(1.09 \\
1.82)\end{array}$ & $\begin{array}{l}1.02 \\
(0.22, \\
1.82)\end{array}$ & $\begin{array}{c}1.70 \\
(1.39 \\
2.01)\end{array}$ & $\begin{array}{c}1.83 \\
(1.18, \\
2.48)\end{array}$ & - & $\begin{array}{l}2.26 \\
(1.84, \\
2.68)\end{array}$ \\
\hline $\begin{array}{l}\text { Elobixibat v } \\
\text { Placebo }\end{array}$ & - & - & - & $\begin{array}{c}2.25 \\
(1.42,3.58)\end{array}$ & $\begin{array}{l}1.74 \\
(1.06, \\
2.87)\end{array}$ & $\begin{array}{r}2.25 \\
(1.42 \\
3.58)\end{array}$ & $\begin{array}{l}1.46 \\
(0.54 \\
2.38)\end{array}$ & $\begin{array}{l}1.42 \\
(0.25 \\
2.59)\end{array}$ & $\begin{array}{c}3.09 \\
(2.05 \\
4.13)\end{array}$ & $\begin{array}{r}1.79 \\
(0.72 \\
2.86)\end{array}$ & $\begin{array}{c}1.18 \\
(-0.06, \\
2.42)\end{array}$ & $\begin{array}{l}3.27 \\
(2.11, \\
4.43)\end{array}$ \\
\hline $\begin{array}{l}\text { Lubiprostone } \mathbf{~} \\
\text { placebo }\end{array}$ & - & - & - & - & - & - & - & - & - & $\begin{array}{l}1.92 \\
(1.35 \\
2.49)\end{array}$ & - & - \\
\hline
\end{tabular}


Drug: Standard dose, Low dose, High dose. Prucalopride: 2mg QD, 1 mg QD, 4mg QD.

Velusetrag: 30mg QD, 15mg QD, 50mg QD. Tegaserod: 6mg bid, 2mg bid, no high dose.

Linaclotide: 145/150mcg QD, 75mcg QD, 290/600mcg QD.

Elobixibat: 10mg QD, 5mg QD, $15 \mathrm{mg}$ QD. Lubiprostone: $24 \mathrm{mcg}$ bid, no low and high dose. 
Nelson, Camilleri, et al. - 33 -

\section{FIGURE LEGENDS}

Figure 1: Flow diagram of included studies identified for systematic review.

Figure 2: Network diagram (CT=clinical trials, $\mathrm{P}=$ patients)

Figure 3: Comparisons between treatment vs. placebo of primary endpoints, $\geq 3$ CSBM/week

| (panel A) or increase over baseline by >1 CSBM/week (panel B), and secondary endpoints, change in CSBM from baseline (panel C) and change in SBM from baseline (panel D). 